دراسات في آثار الوطن العربي 11

\title{
لوحة التقدمة الرئيسية لمقبرة حوى نفر بسقارة
}

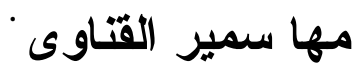

موقع مقبرة حوى نفر وأهم أعمال الحفائر بها:

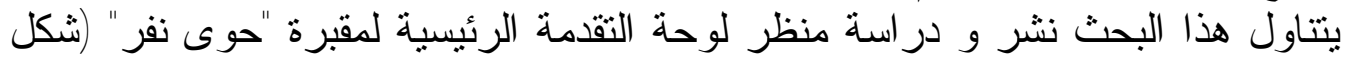

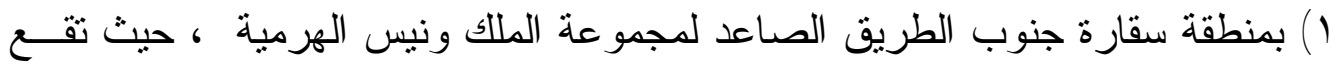

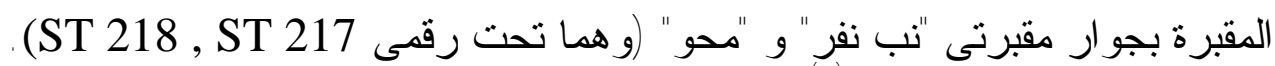

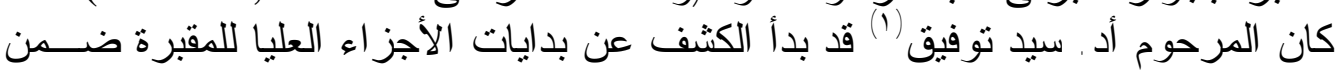

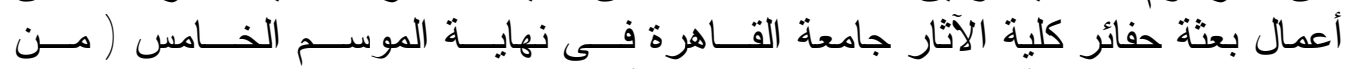

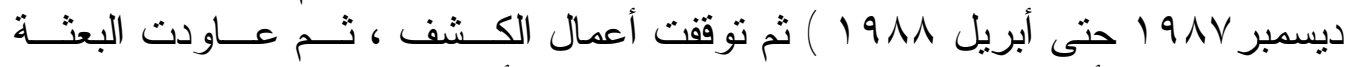

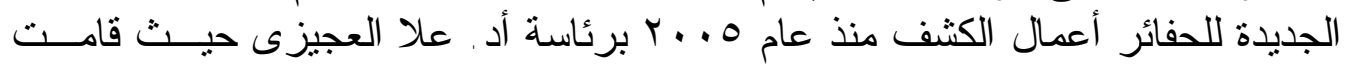

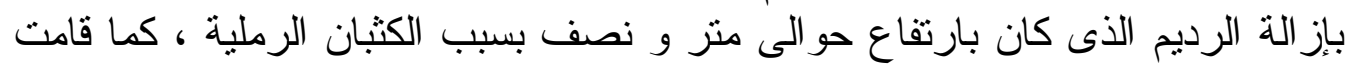

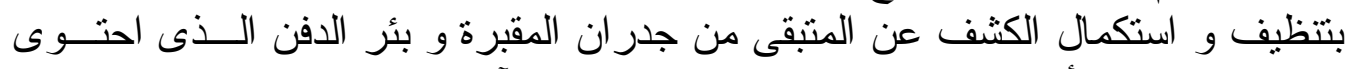

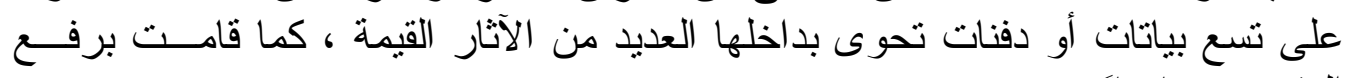

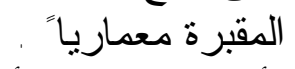

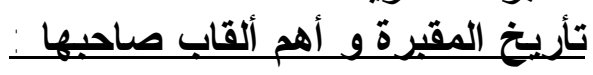

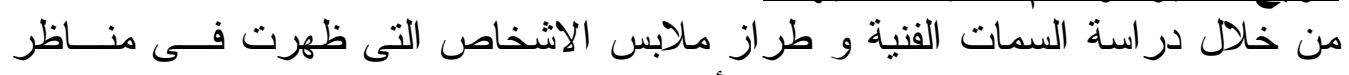

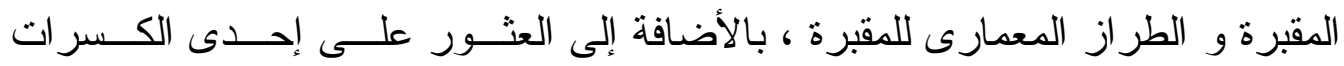

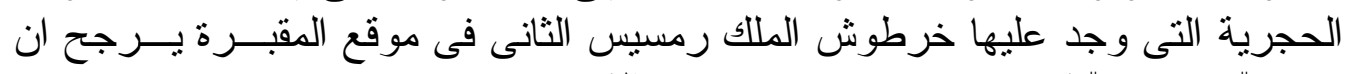

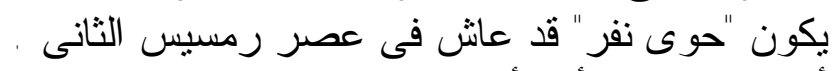

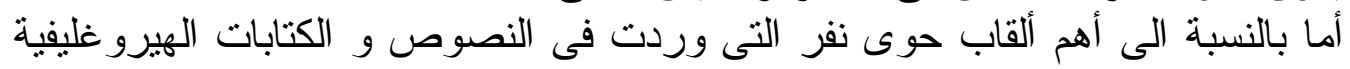

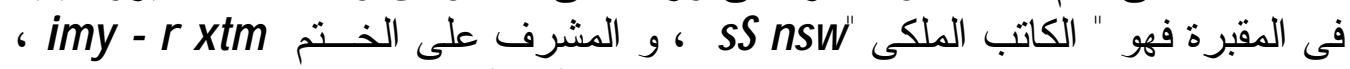

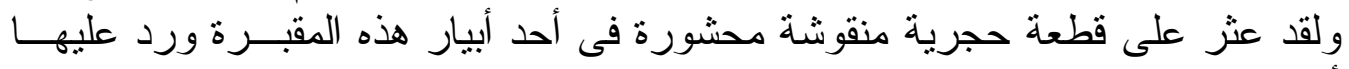

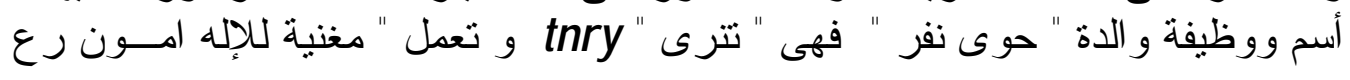

• أستاذ مساعد - كلية الآثار - جامعة القاهرة • أتقام بخالص الثكر و التقدير للأستاذة الدكثورة علا العجيزى لسماحها لى ولزملاثئ بالنشر العلىى

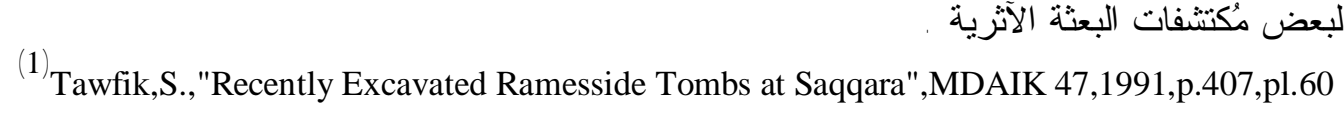


ملك الآلهه " (r) ومن ثم فأن مقبرة حوى نفر تعتبر و احدة من ضمن مجموعـــة مقــابر

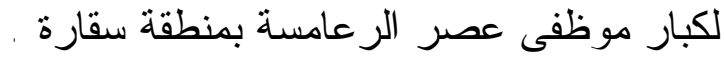

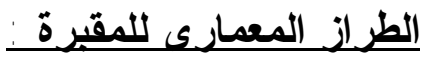

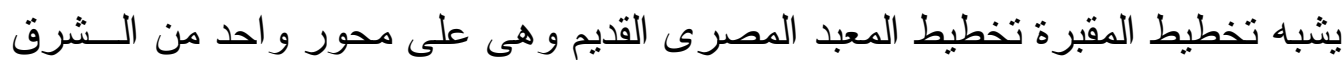

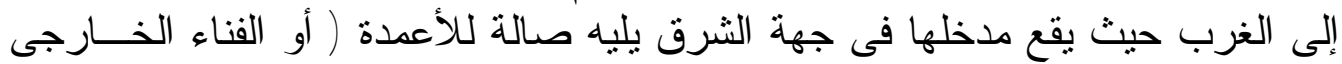

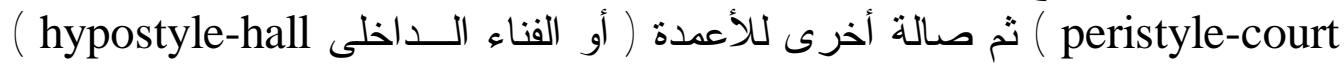

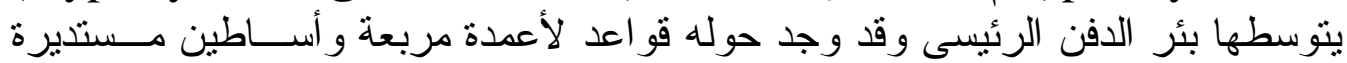

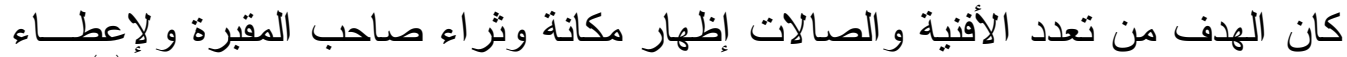

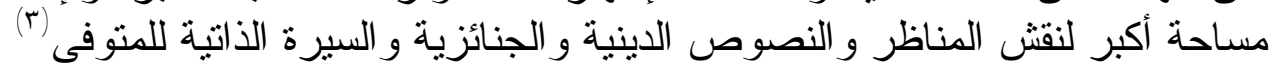

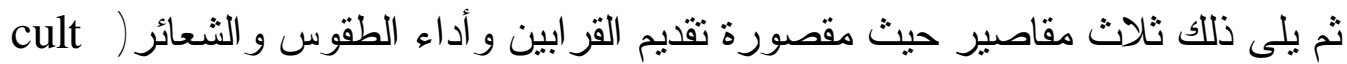
(room

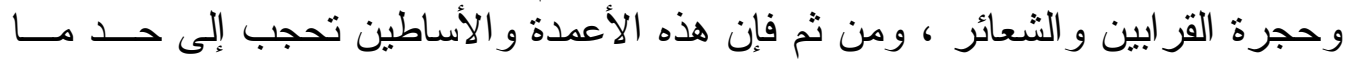

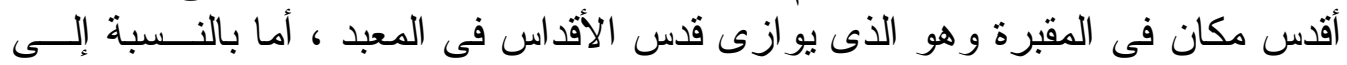

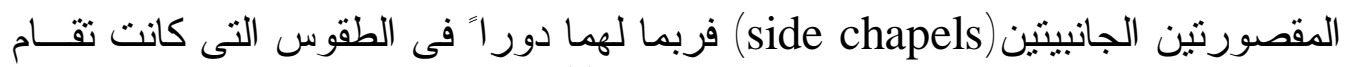

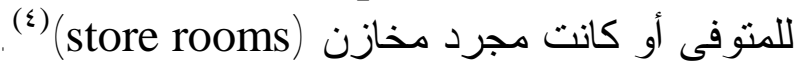

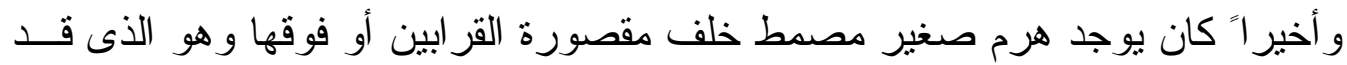

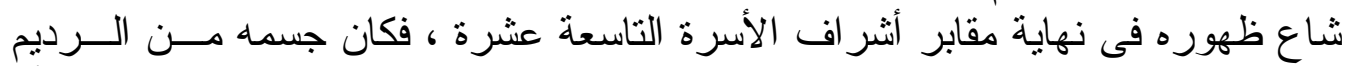

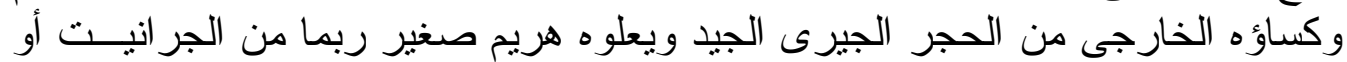

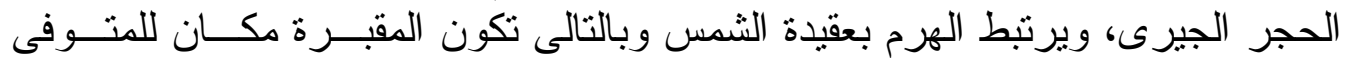

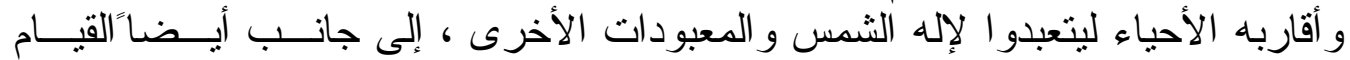

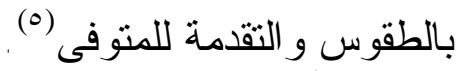

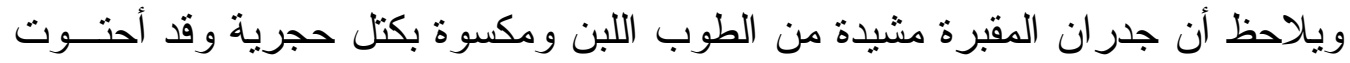

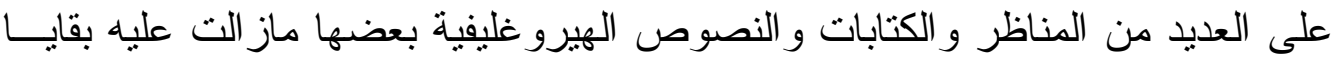
موقع اللوحة محل الدر اسة وأهميتها :

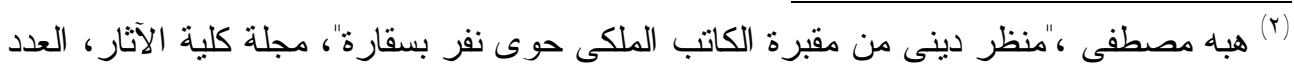

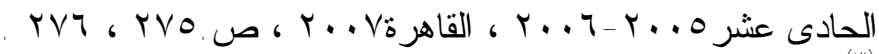

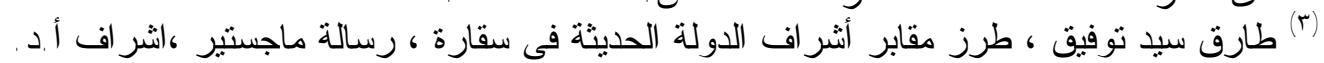

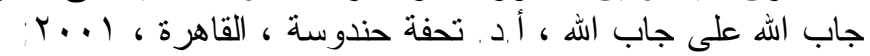
Tawfik, S., op.cit., 408; Martin,G.T., The Tomb Chapels of Paser and Raaia at Saqqara,

London ,1985, p.6

${ }^{4}$ Tawfik,S., op.cit. , 40

5

Ibid,408 


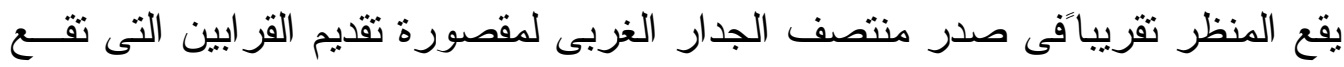

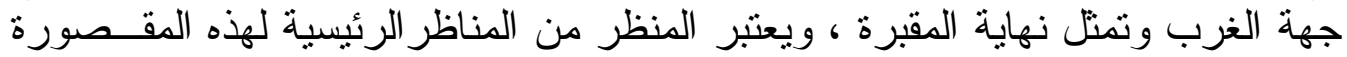

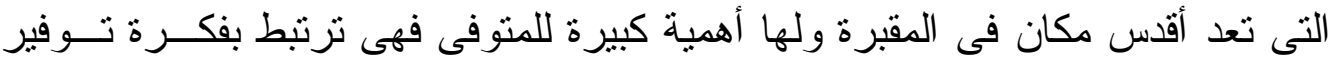

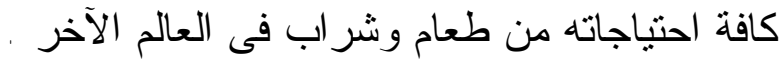

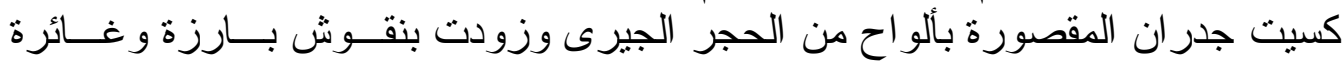

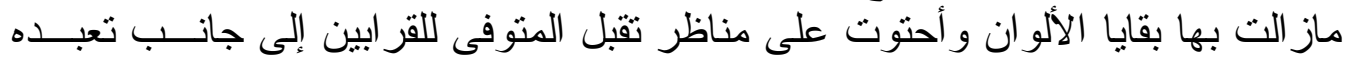

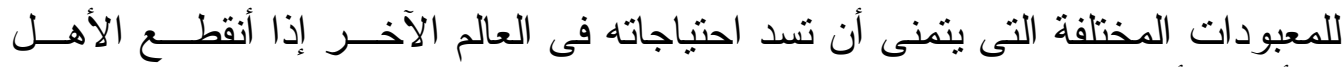
و الأقارب أو الكهنة عن تقديم القر ابين فى الفى المقبرة .

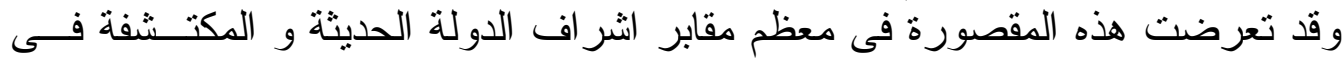

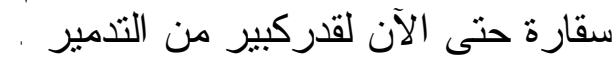

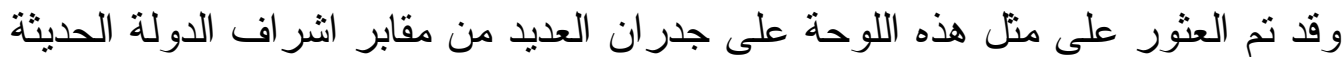

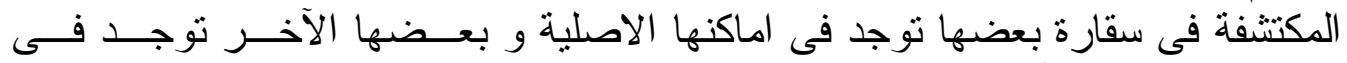

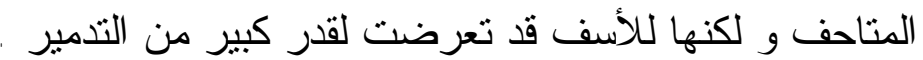

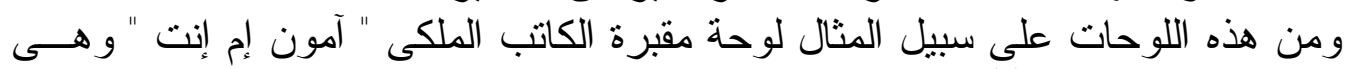

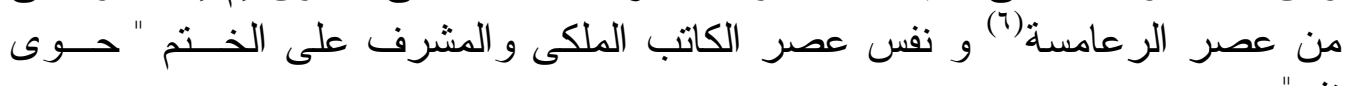
نفر" " نون

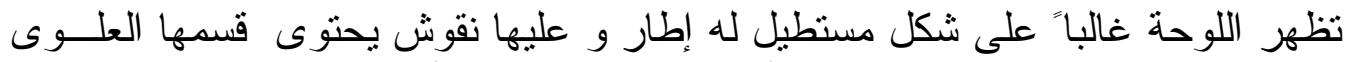

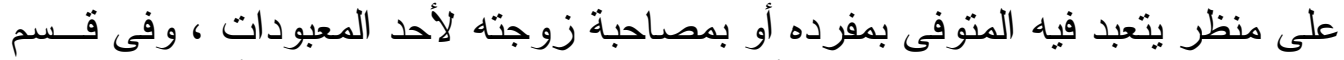

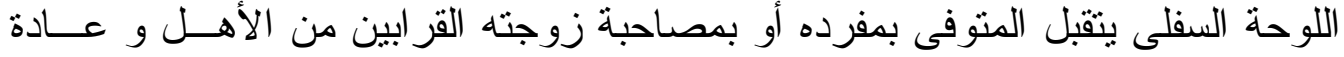

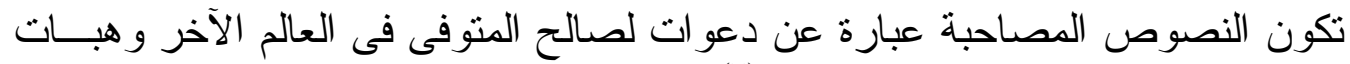

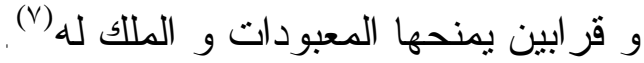

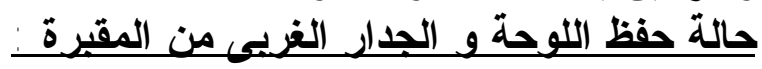

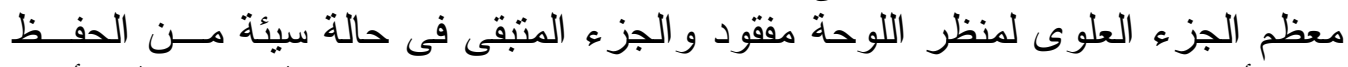

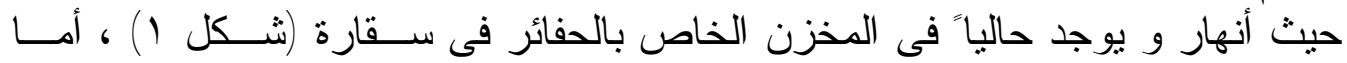

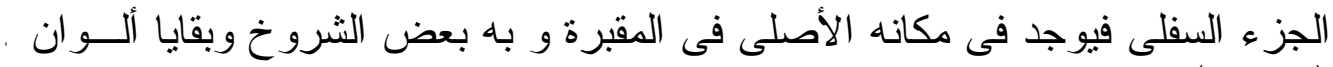

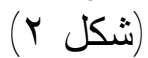

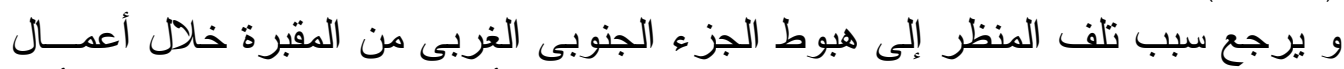

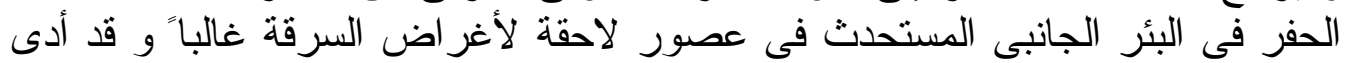

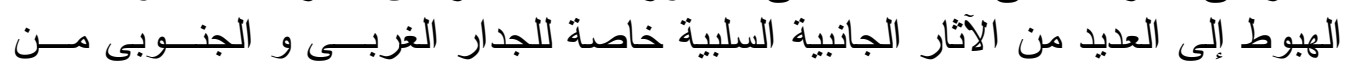

6 Gohary,S.,"The Tomb-Chapel of The Royal Scribe Amenemone at Saqqara,"BIFO 91, 1991,pl.58 a

طارق سيد توفيق ، المرجع السابق ، ص^^זا. 


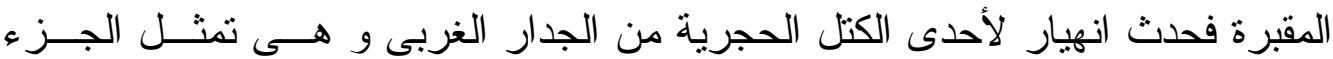

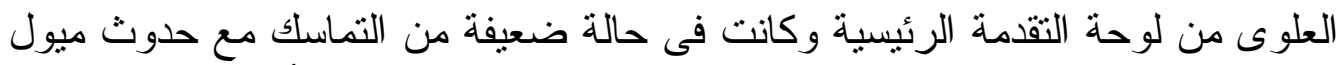

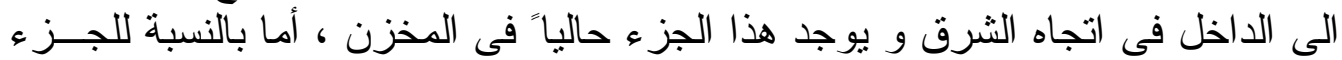

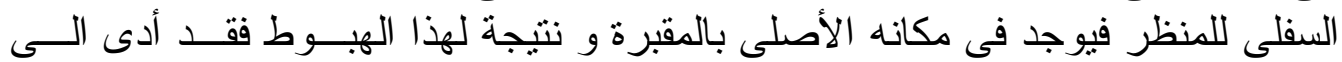

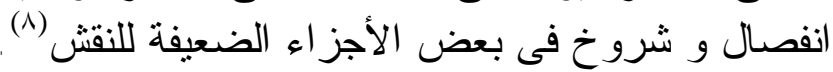

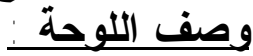

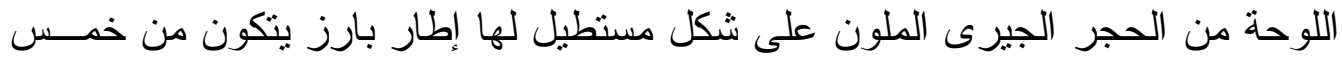
خطوط عرضية فى الجانب السفلى ، عليها نقش بارز لمنظر تقدمة ينقسم إلى جـزئئين

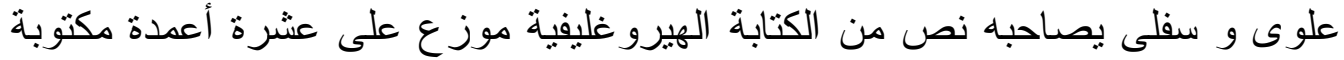

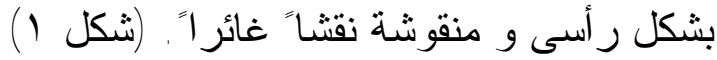

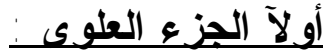

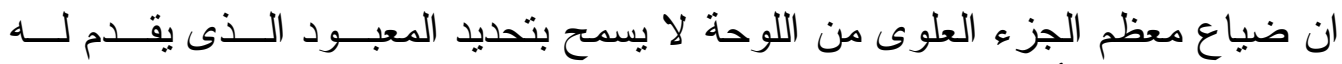

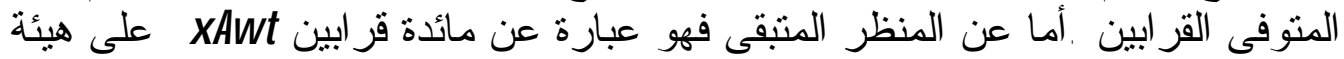

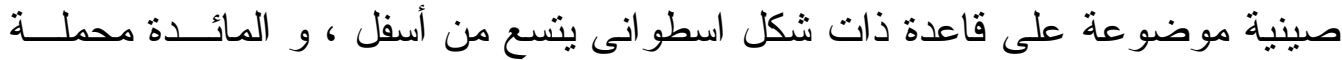

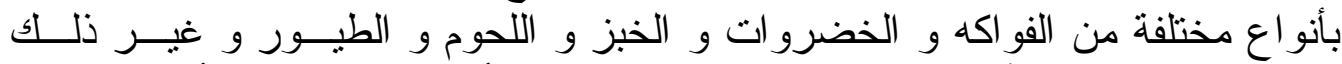
فالطعام هو القوة والتأثير المهيمن على الثعائر، ونجد أسفل المائدة ثلاثنة أو انى تحتوى

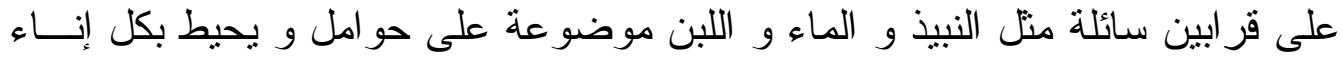

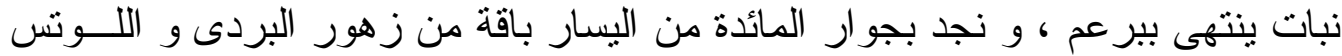

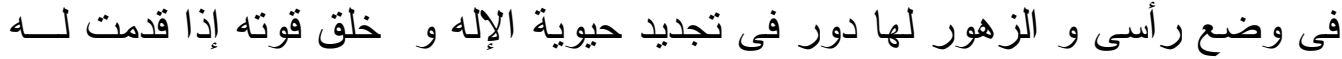

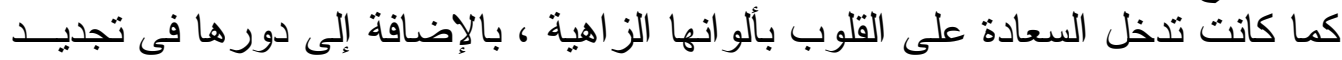

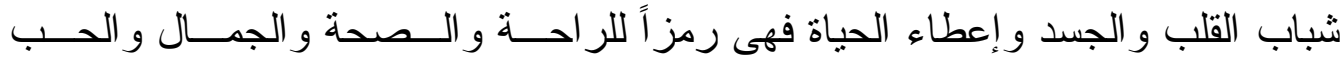

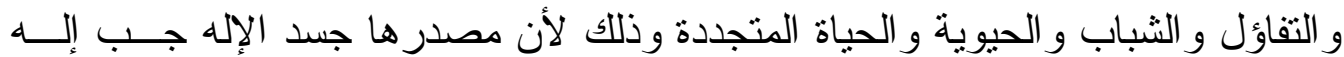

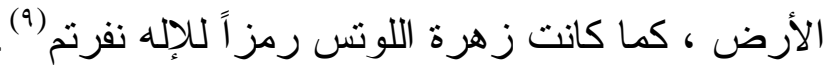

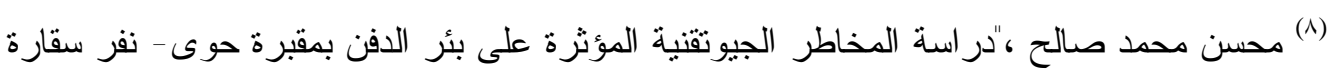

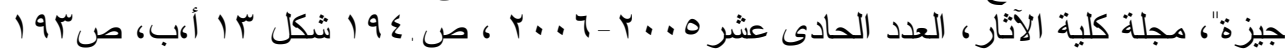

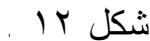

Brunner-Traut,E.,in: LÄ I (1979),837ff.;Faulkner,R.O.,The Ancient Egyptian

Pyramid Texts, Oxford, 1969,264,266a; Daumas,F.,Les Mammisis de Dendera,IFAO, Le Caire, 1959,46(7) ; Chassinat,E et Daumas,F.,Le Temple de Dendera,vol.6-8,Le Caire, 19651978,VII,176(10); Harer,B.W.,"Lotus"in:The Oxford Encyclopedia of Ancient Egypt, 2001,vol.2,305;

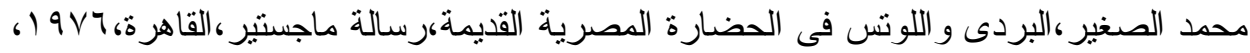
$0 .: 0 \leqslant$ 


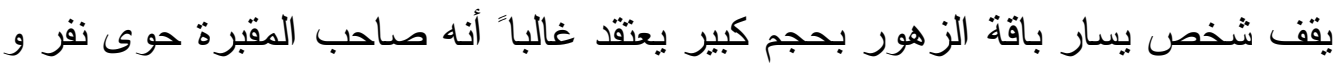

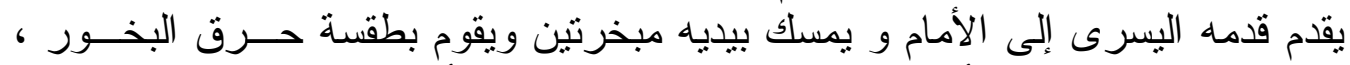

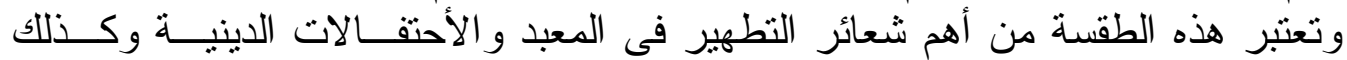

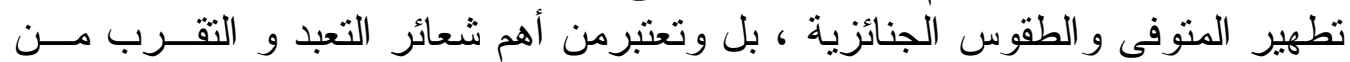

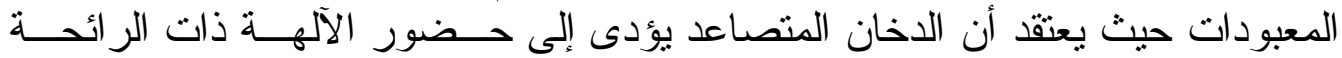

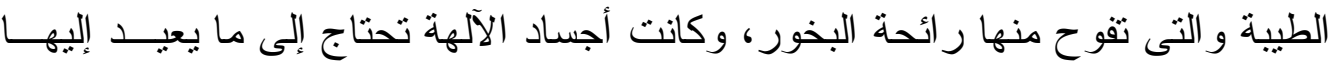

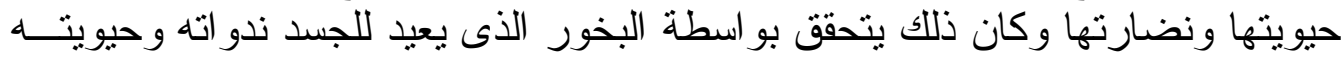

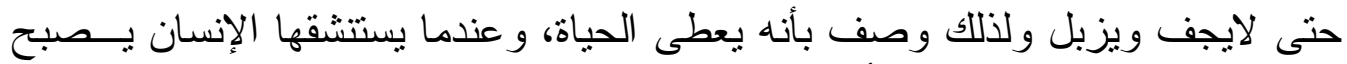

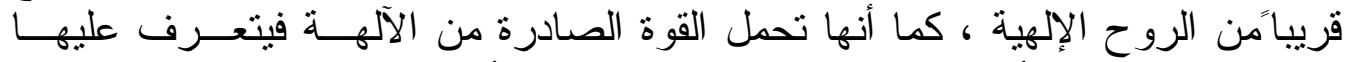

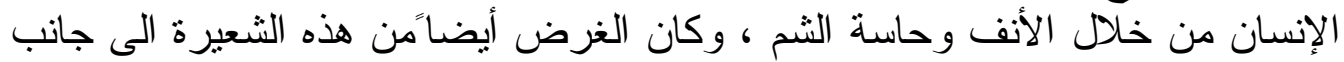

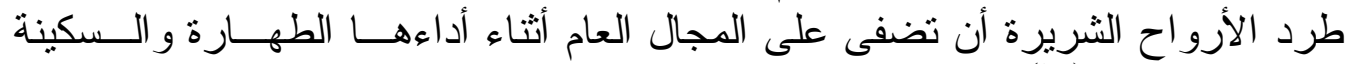

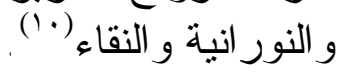

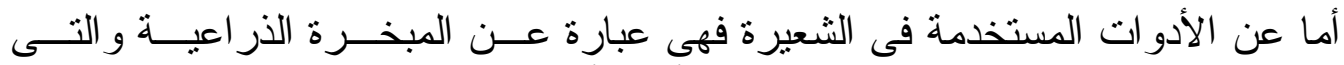

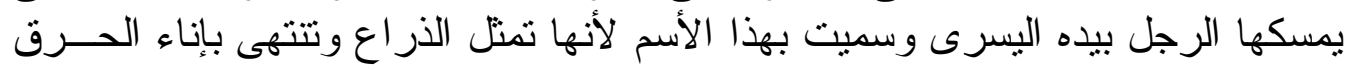

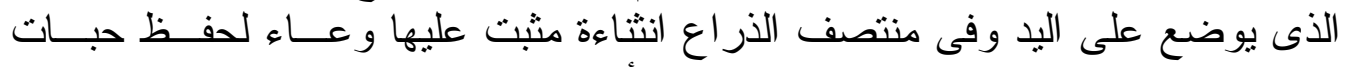

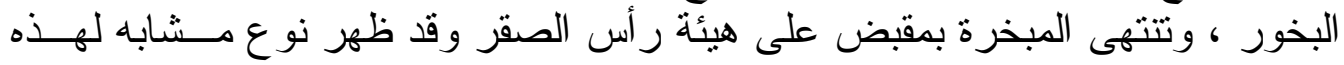

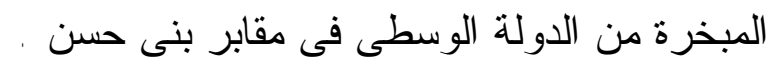

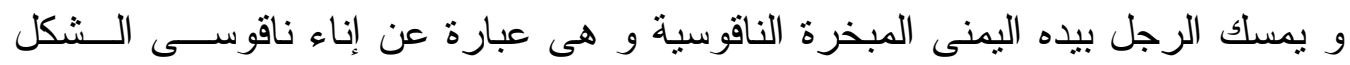

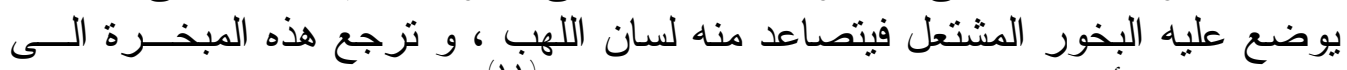

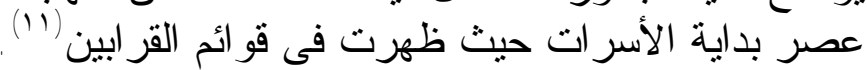

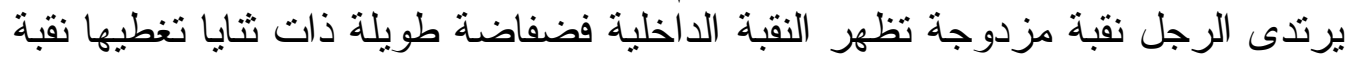

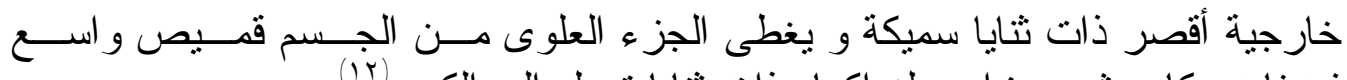

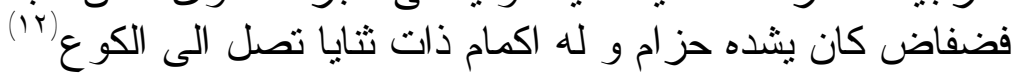

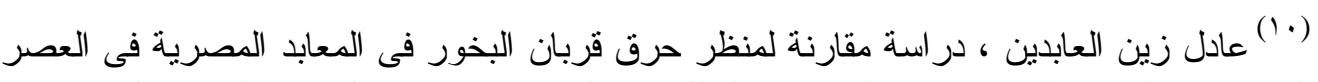

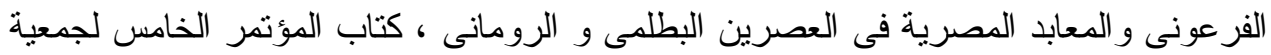

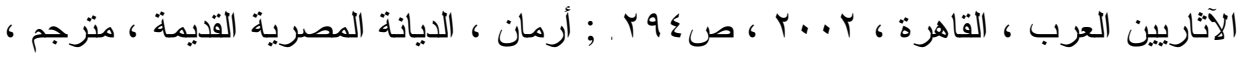

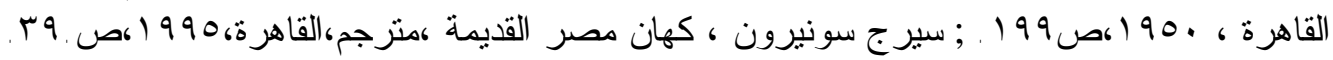
Blackman, A.M.,"The Significance of Incense and Libations in Funerary and Temple Ritual", in: ZÄS 65(1930), 73.

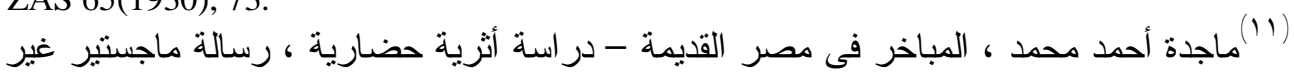

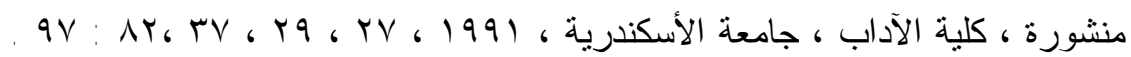

12 Staehelin,E.,Untersuchungen zur agyptischen Tracht im alten Reich, in:MÄS8 , (1966) 


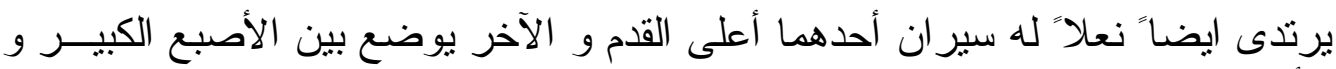

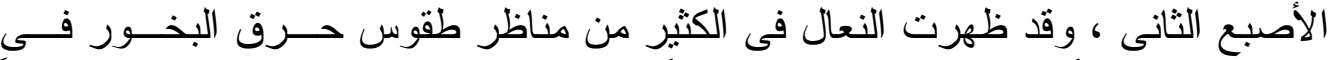

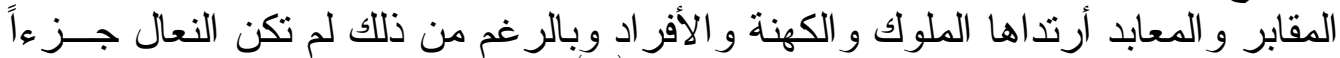

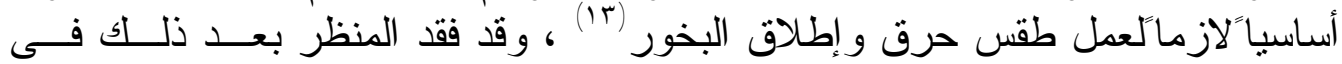
اللوحة النائا

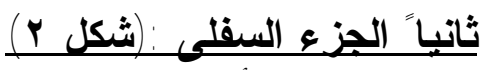

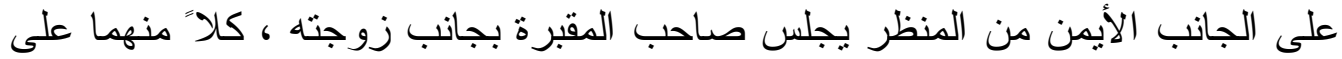

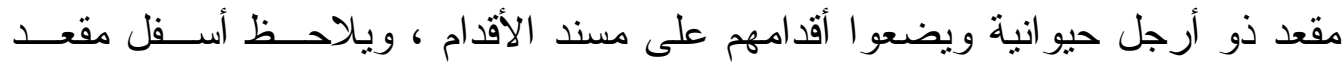

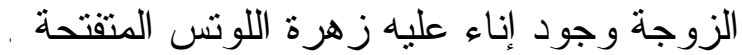

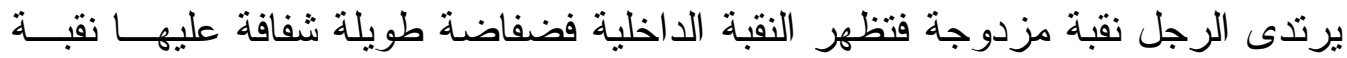

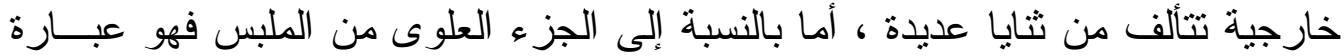

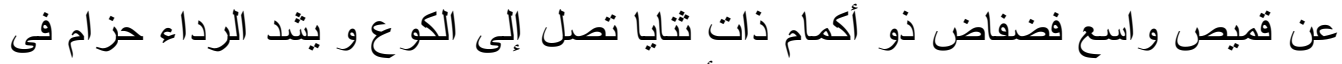

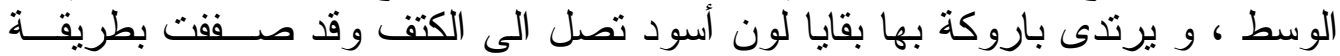

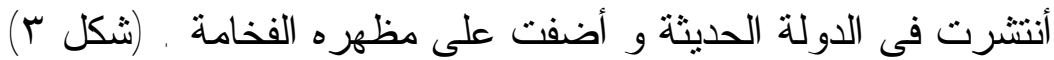

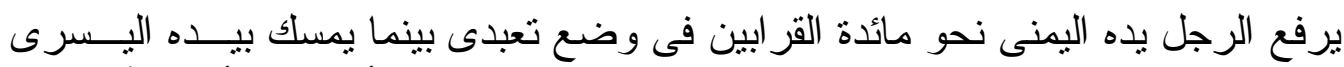

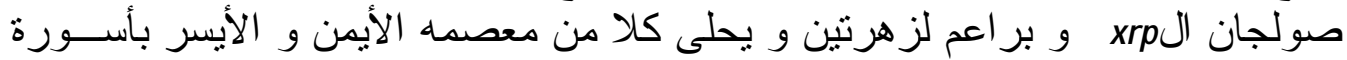

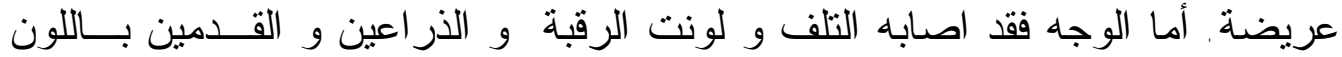

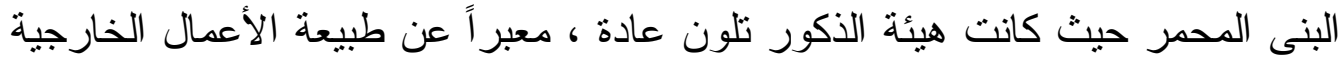

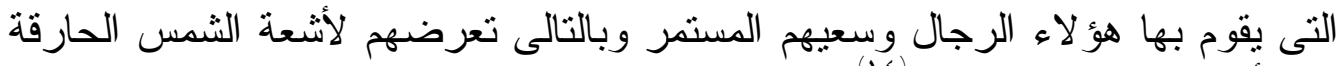

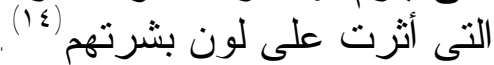

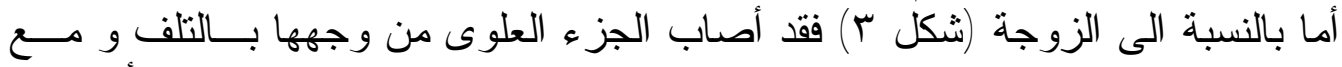

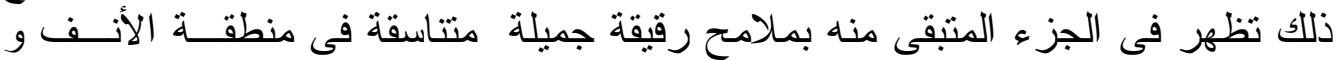

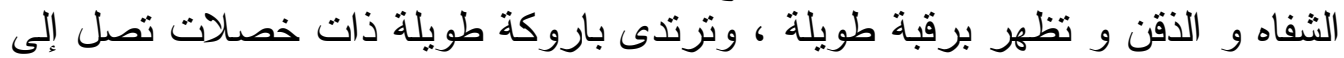

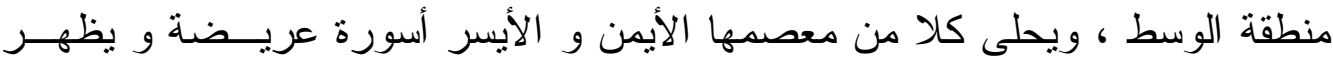

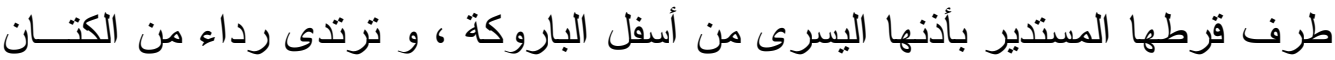

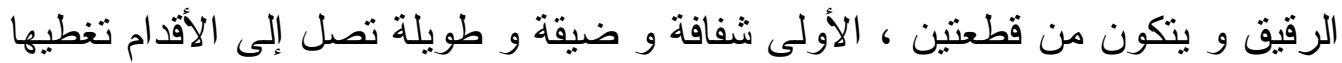

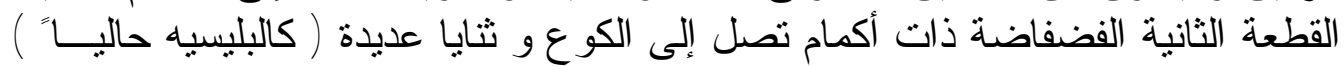

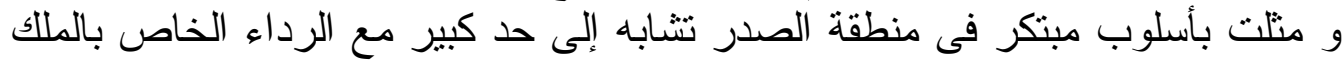

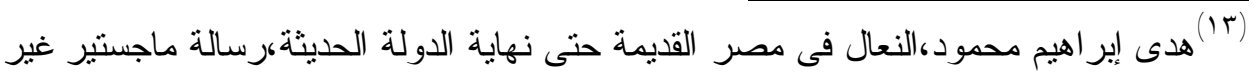

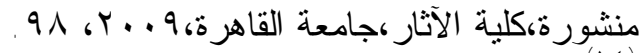

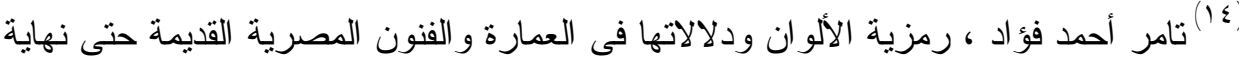

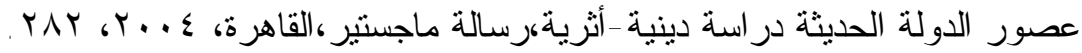
Staehelin,E.,"Hautfarbe"in:LÄ II,1069 
سيتى الأول من الأسرة التاسعة عشر الذى ظهر به فى تمثاله المصنوع من الثشت (10)

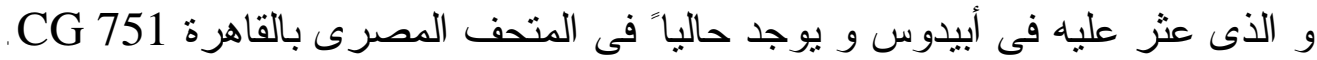

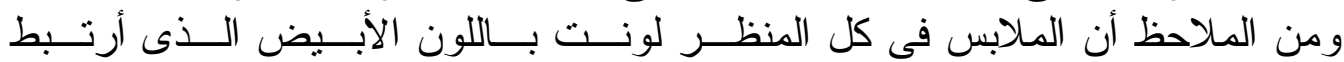

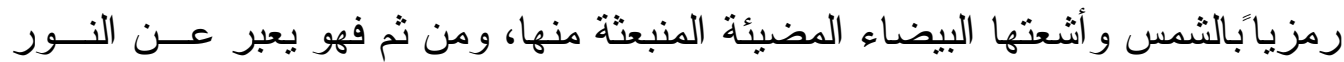

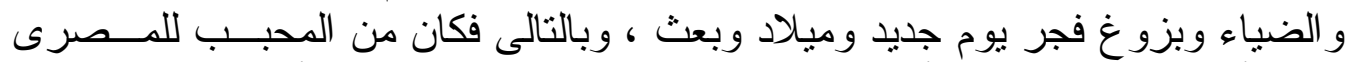

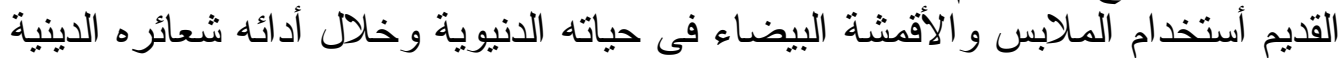

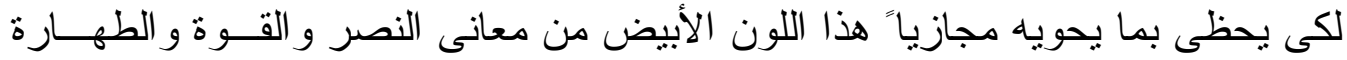
و القداسة و الحماية الإلكية لهية (17)

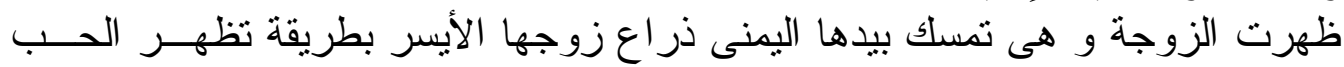

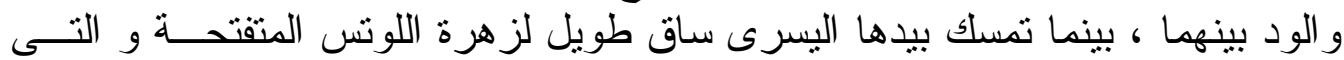

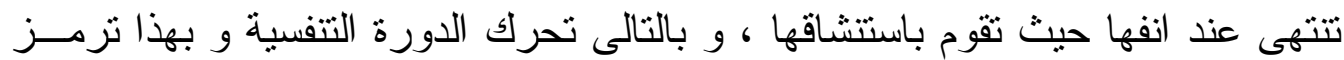

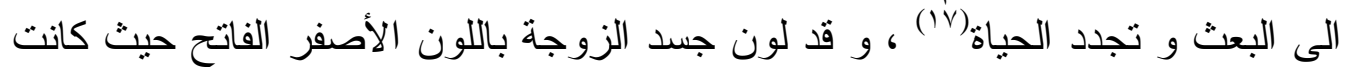

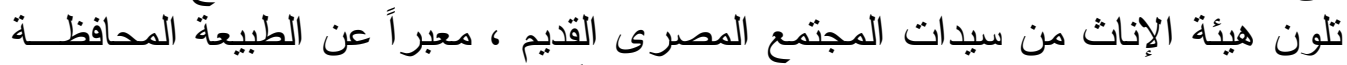

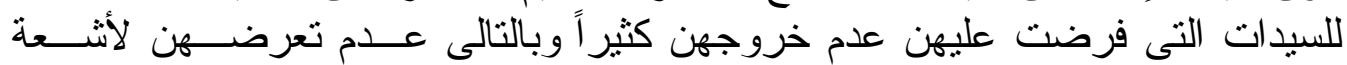

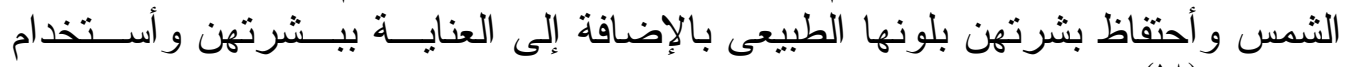

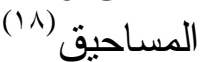

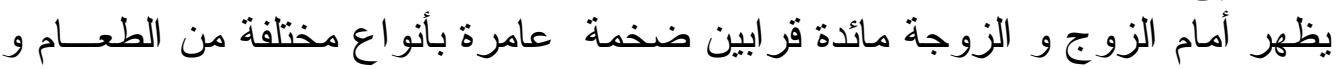

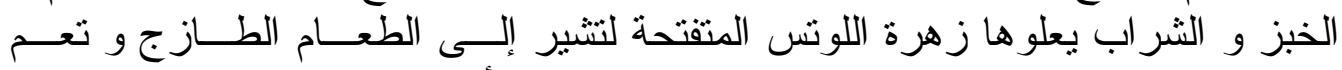

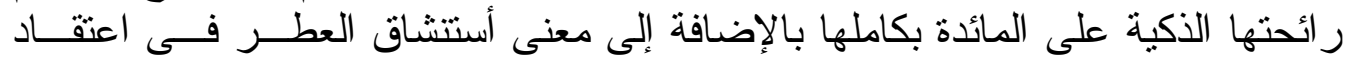

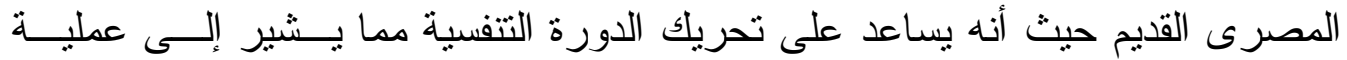

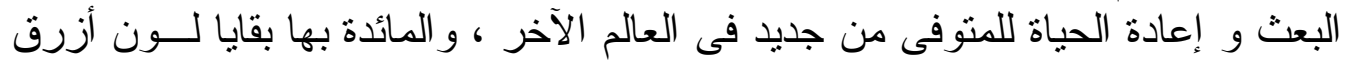

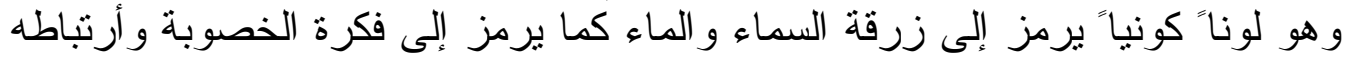

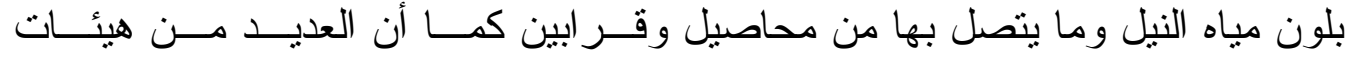

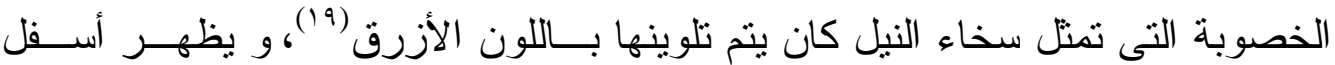

15 Tiradritti,F.,"The End of the New Kingdom “in: The Treasures of the Egyptian Museum, Cairo,2000,256.

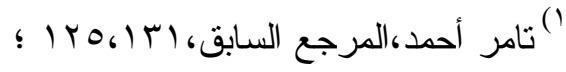

Wilkinson,R.,Symbols and Magic in Egyptian Art,London,1994,109; Lurker, M., The Gods and Symbols of Ancient Egypt, London, 1980,129.

17

Harer,B.W.,op.cit.,305

$$
\text { (1^) }
$$

Staehelin,E.,op.cit.,1o69; Bunson,M.,A Dictionary of Ancient Egypt,Oxford,1995,55.

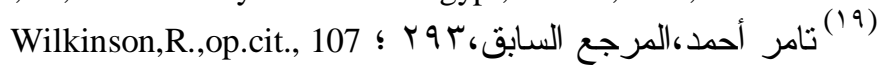




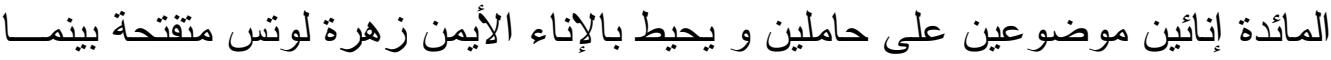

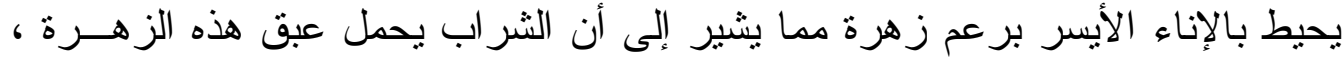

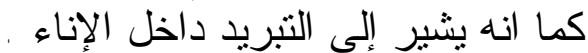

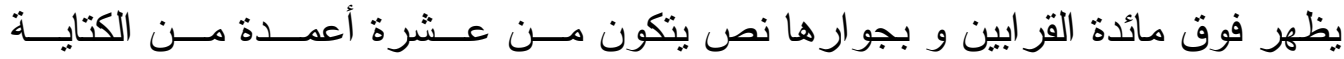

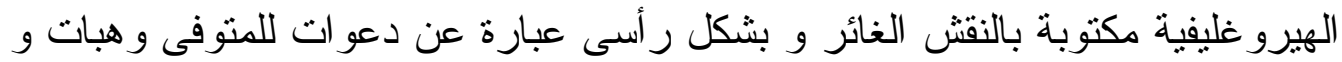

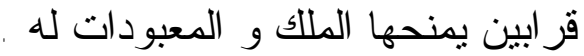

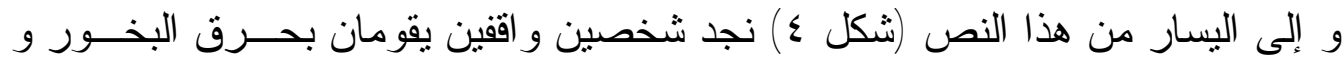

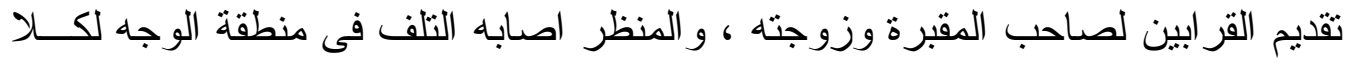

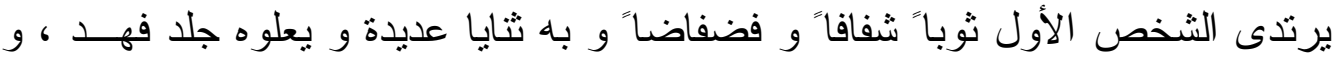

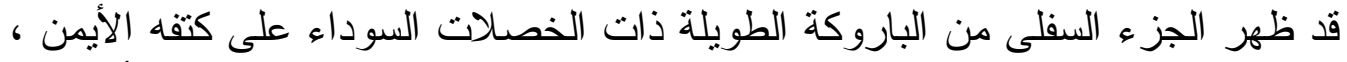

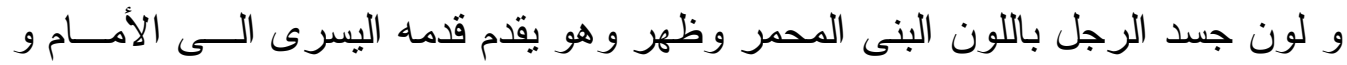

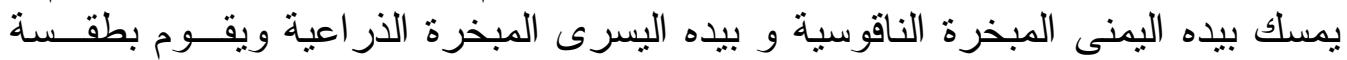

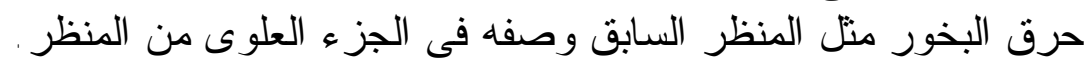

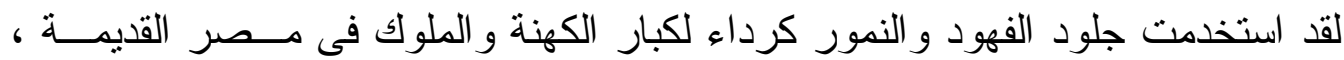

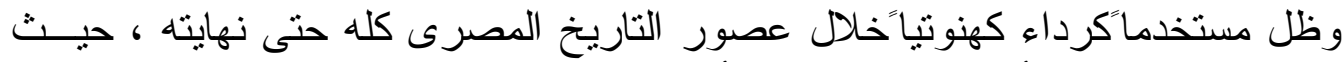

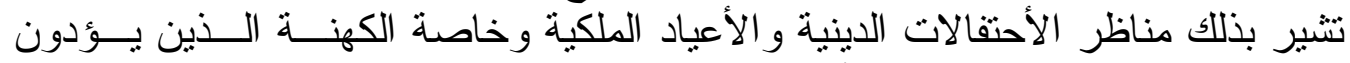

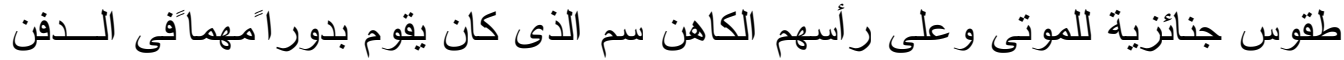

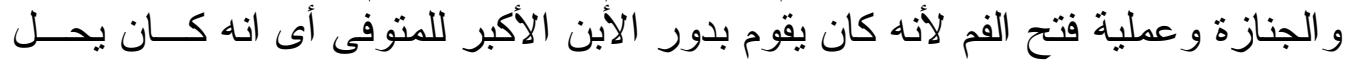

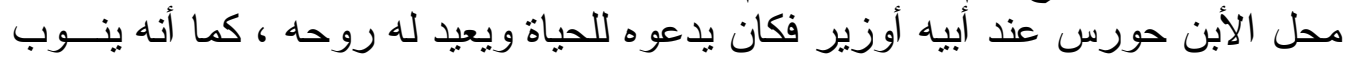

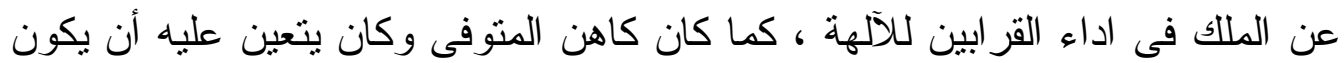

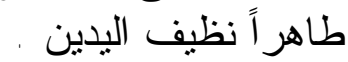

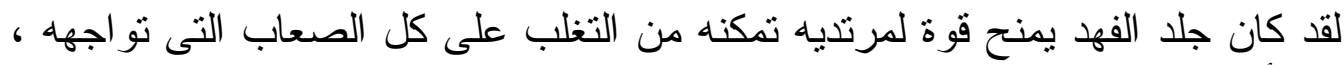

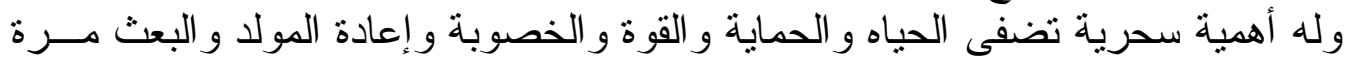

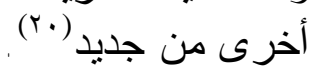

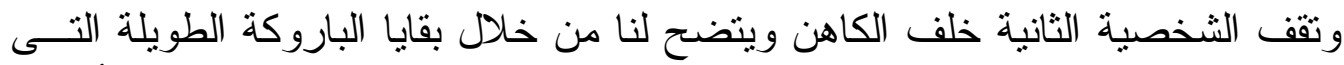

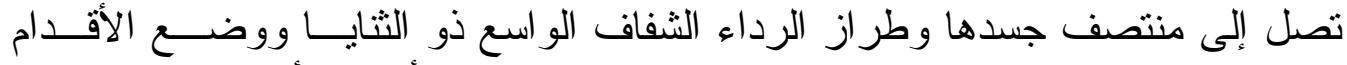

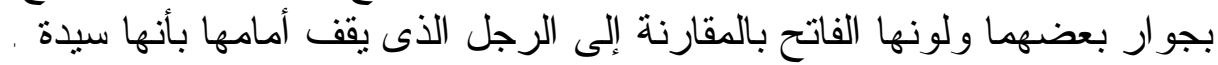

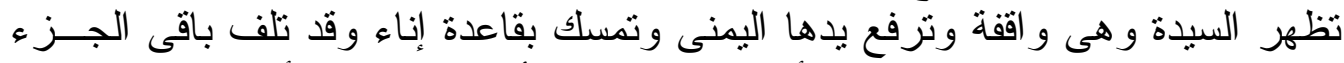

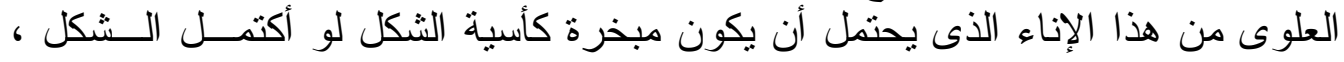

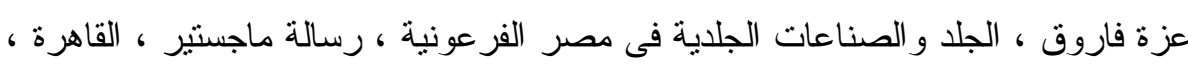

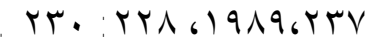


بينما تمسك بيدها اليسرى أجنحة طائرين وقد لون رأس أحداهما باللون الأزرق كرمز

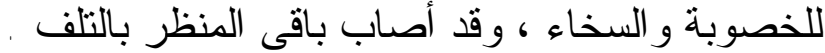

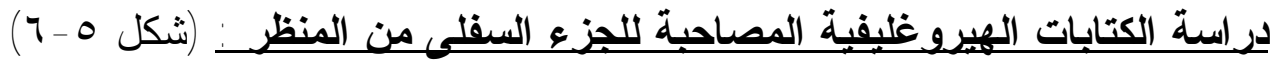

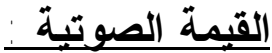

(1) $\mathrm{n} \mathrm{kAn} \mathrm{///////}$

(2) in sn

(3) .f sS nsw mAa

(4) mry .f imy - r pr

(5) $w r n n b n H H$

(6) nb nfr mAaxrw Dd .f Htp di nsw ///// nbt tnw wbx .n

(7) $\mathrm{Ra} / / / / / \mathrm{xAbs} / / / / / \mathrm{m}$ nhpw t wab pri m Hwt-aAt

(8) Hr xAwt n nbw (n) nHH di (.sn) irtt n kAn rn n sS nsw mAa

(9) mw Hr .f ////// TAw $n$ fnd .f Wsir imy-r xtm Hwy nfr (10) $\mathrm{m} / / / / / \mathrm{sn} . \mathrm{f}$

\section{الترجمة}

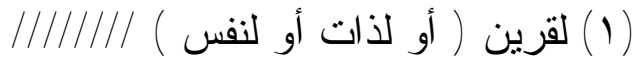
(r)

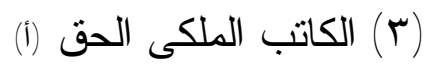

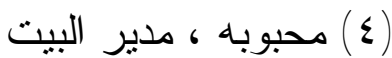

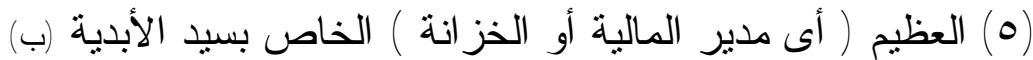

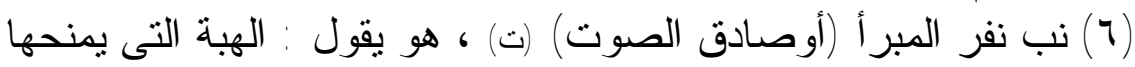

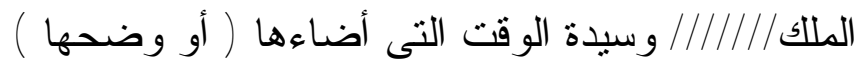

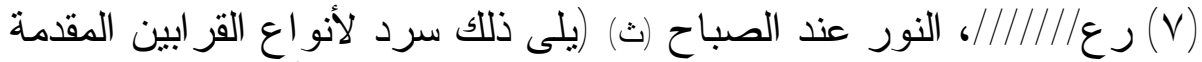
وهى:) الخبز (ج) الطاهر (ح) الآتى من البيت الكبير ( أى : الضيعة الملكية )

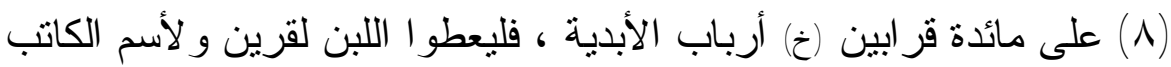

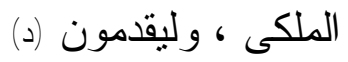
(9) المياه له |||||/| و الأنفاس لأنفه ، لأجل أوزير (المتوفى) ، المشرف على الختم (ذ) ، حوى نفر أخيه

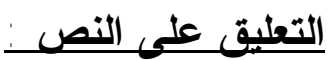
(أ) أكاتب الملكى الحق ، وهو لقب من ضمن ألقاب عديدة تقلدها

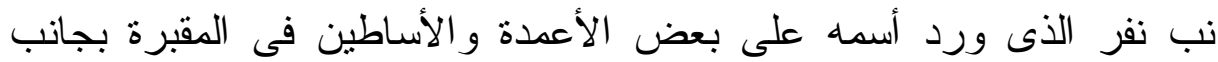
حوى نفر، ويتضح من النص السابق بأنهما أخوة غالباوَّد أخذ هذا الأن اللقب 
أيضاً حوى نفر ونب نفر صاحب المقبرة المجاورة ، ومن الملاحظ أن الصفة

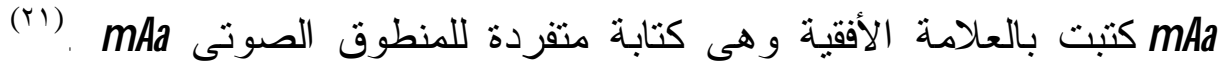
ويشير اللقب SS nSW فى عصر الرعامسة إلى ثقة الملك الكبيرة في صنى صاحبه

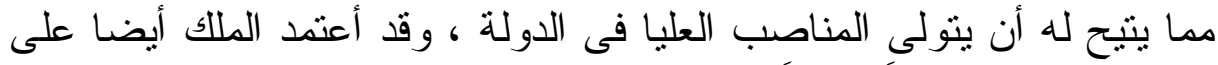

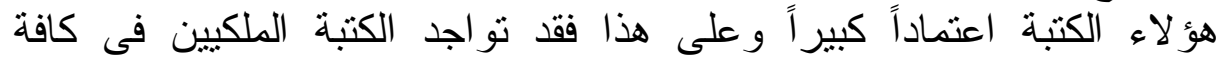

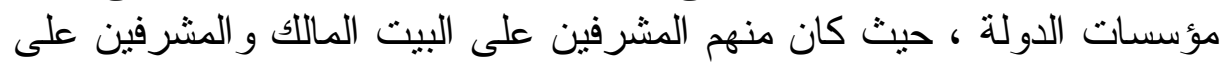

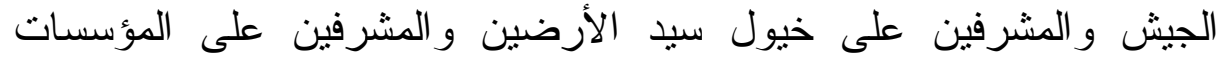

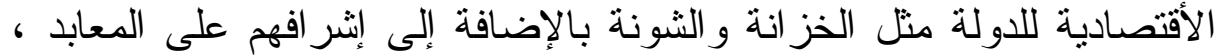

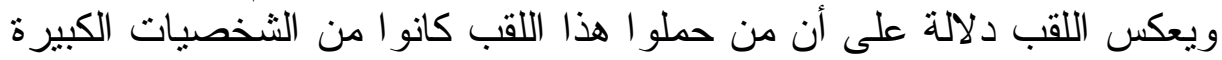

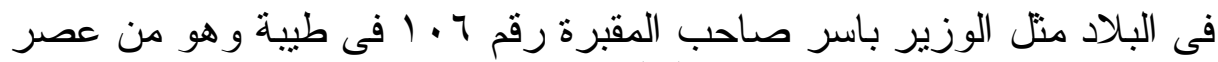

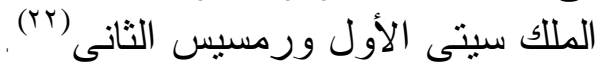

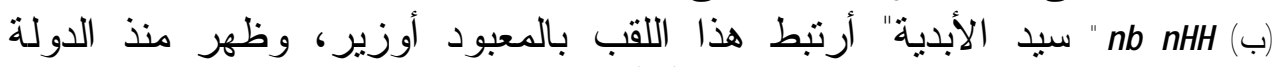

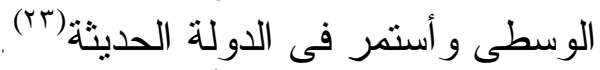

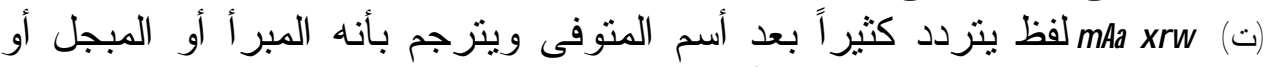

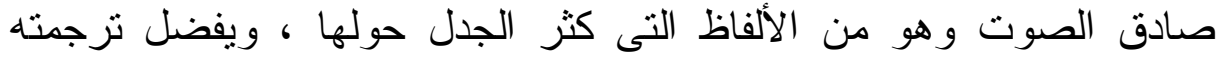

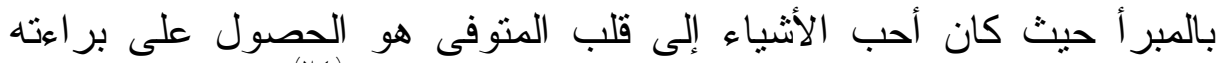

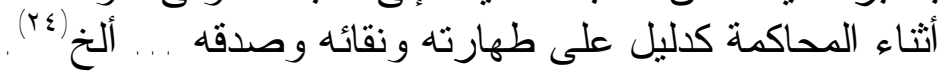

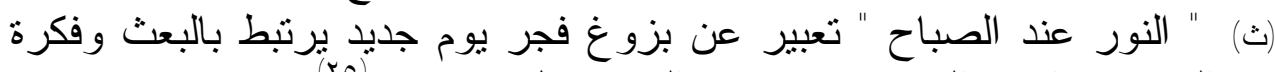

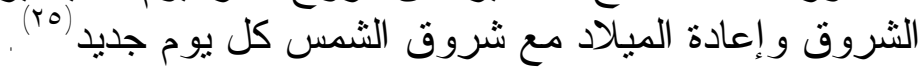

(ج) يجب أن تسنكمل كلمة الخبز بالمخصص $\theta^{\prime}$ (rr)

$$
\text { ; rV9، rVV، rV، هبة مصطفى، المرجع السابق }
$$

Gohary,S.,A Copy Of The Book of The Dead with Variations,in:Bulletin De L'Institut d'égypte,tomes LXX \& LXXI 1989-1990,p.23,fig.1,Text B(1,6); Wb II,13(24)

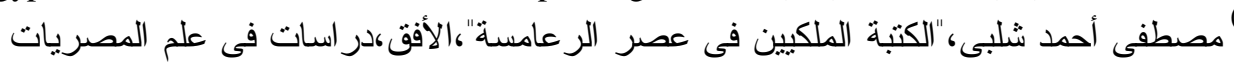

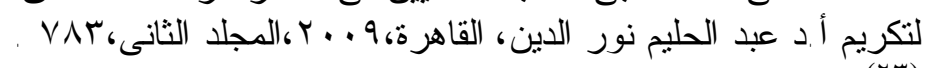

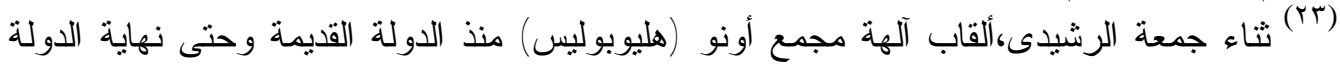

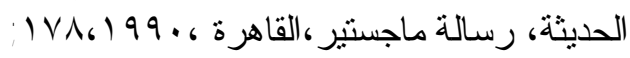

Leitz,c.,Lexikon der ägyptischen Götter.., ,in:OLA 112 Band III 2002,667:669

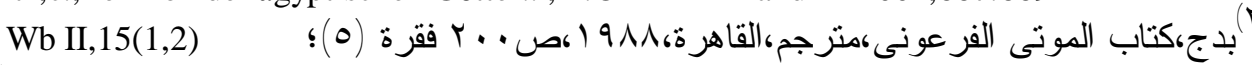

(25) Wilkinson,R.,op.cit.,109; Lurker, M., op.cit, 129

(26) Lesko, IV, 68; Wb V,209,(4) 
(rV) (خAWt بمعنى" مائدة قر ابين" كانت للمو ائد أهمية لدى المصرى القديم حيث خصصست لوضع الطعام عليها كقربان ، ولقد أثتهر فى مصر القديمة ثلاثة

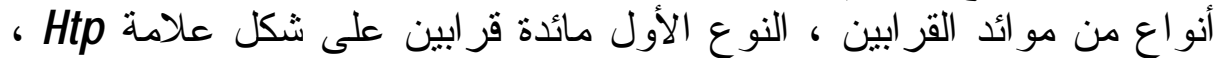
النوع الثانى على شكل علامة WDHW وهى عبارة عن صنية موضو عة على حامل ذى أربعة أرجل ، النوع الثالث على شكل على علامة XAwt او هAyt أسطو انى أو مستطيلة وهى التى وردى فت فى النص و على اللوحة ، وقد قصد

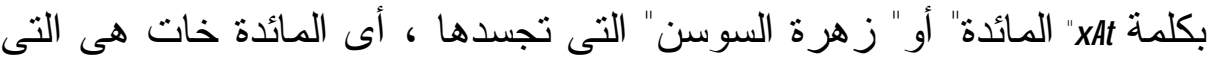

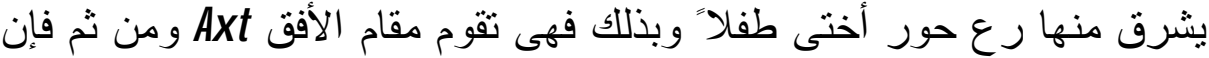
المصرى القديم قد أستخدم التورية والجناس فى الأسماء الواردة فى متون الأهر ام ونصوص التوابيت ليجعل الأفق Axt هو XAt مائدة الطعام ، ويدعم

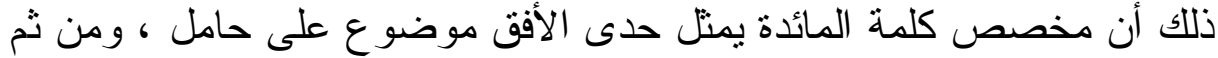
فأن المائدة XAt هى أفق المبلاد أو البعث كأفق رع عند تجدد مولده يومباً، أما بالنسبة إلى تتاول طعام المائدة فهو احتو اء وهضم لكل طاقاتها السحرية

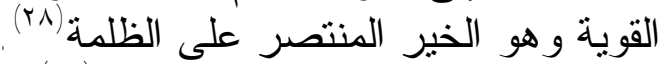

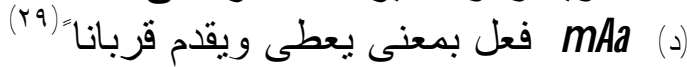

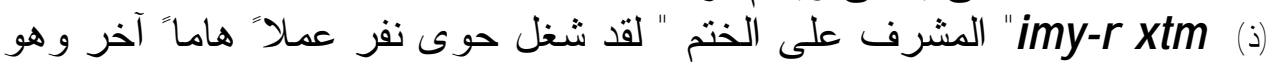
"المشرف على الختم" ، حبيث ساعده حصوله من فبل على وظبفة ولقب "الكاتب الملكى" ليتبو أ هذه المكانة المرموقة التى وصل إلبها .

(27) Lesko, I, 94; Wb I,282,(13)

(r^) علاء الدين محمد قابيل،"الدور الرمزى لمائدة الملك فى العقيدة المصرية" مجلة كلية الآثار - العدد

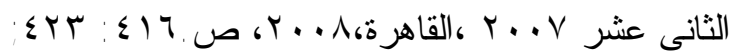

Klebs,L.,Die Reliefs des alten Reiches, Heidelberg,1915,130ff. (29)

Lesko,II, 174; Wb II,22 
1 - يعتبر هذا المنظرمن المناظر الرئيسية فى مقصورة تقديم القر ابين أقدس القدي

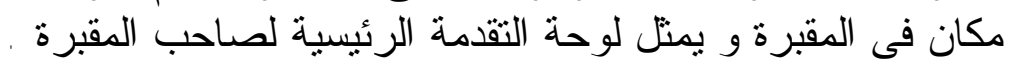

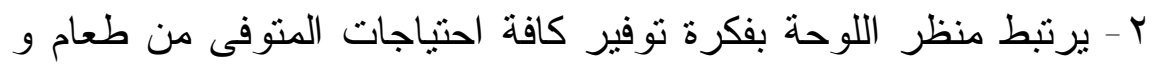

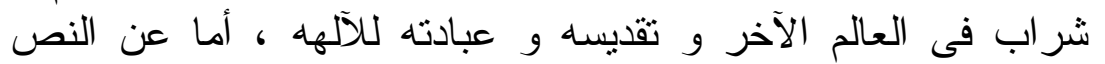

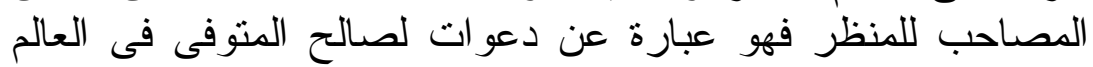

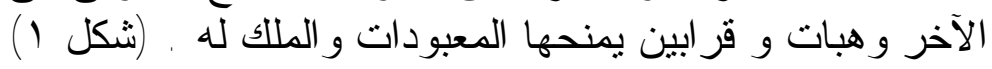

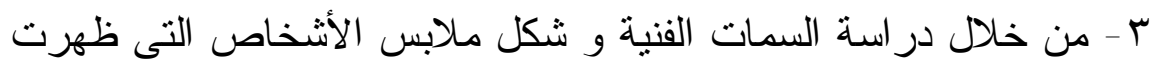

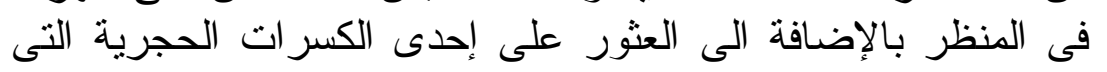

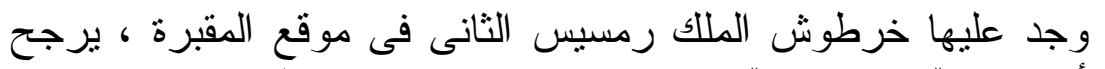

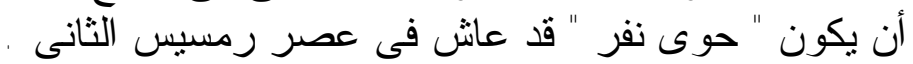

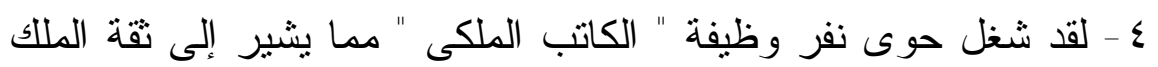

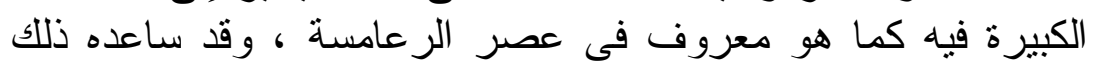

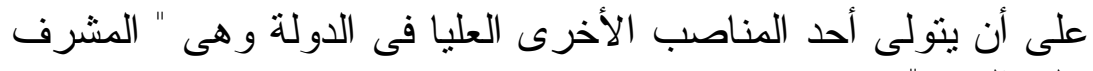

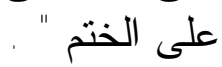

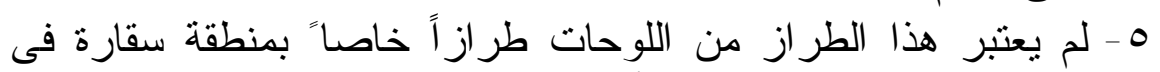

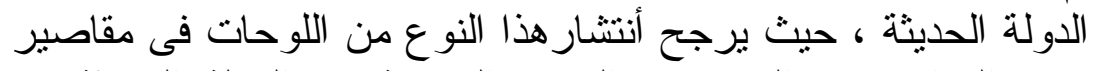

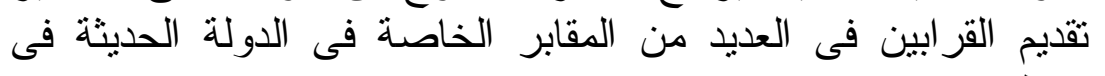
مناطق عديدة .

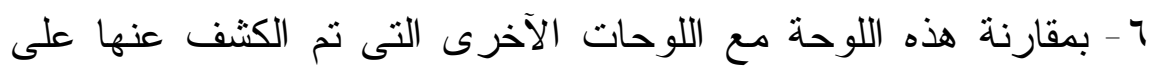

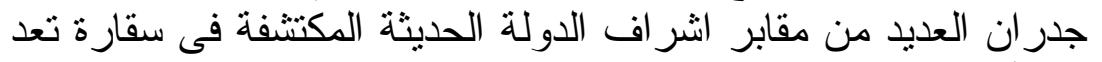

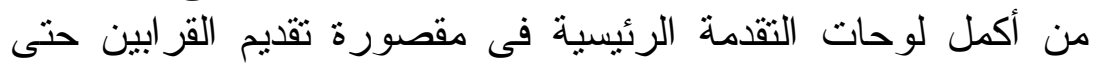
الآن . المبل 
دراسات في آثار الوطن العربي 11

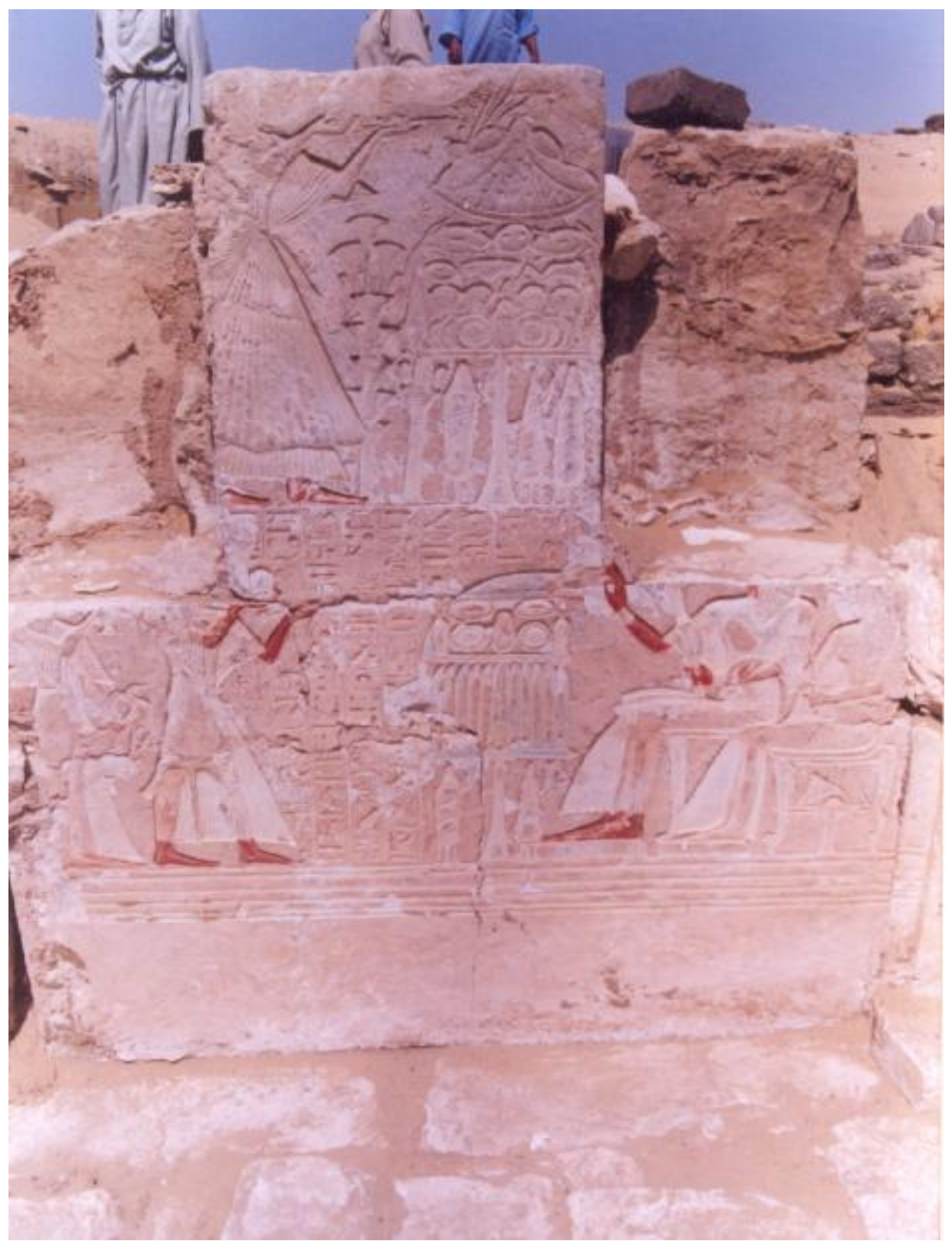

شكل (1) 
دراسات في آثار الوطن العربي 11

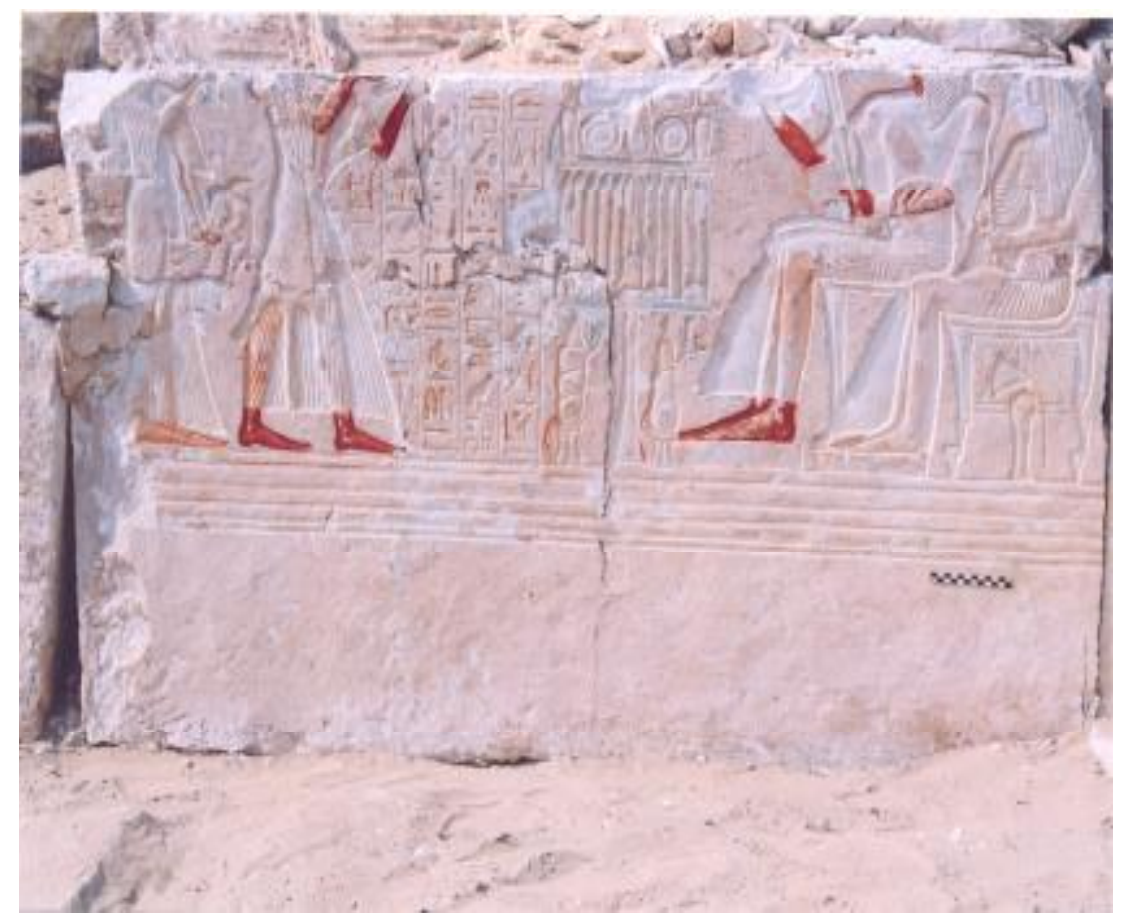

شكل (r)

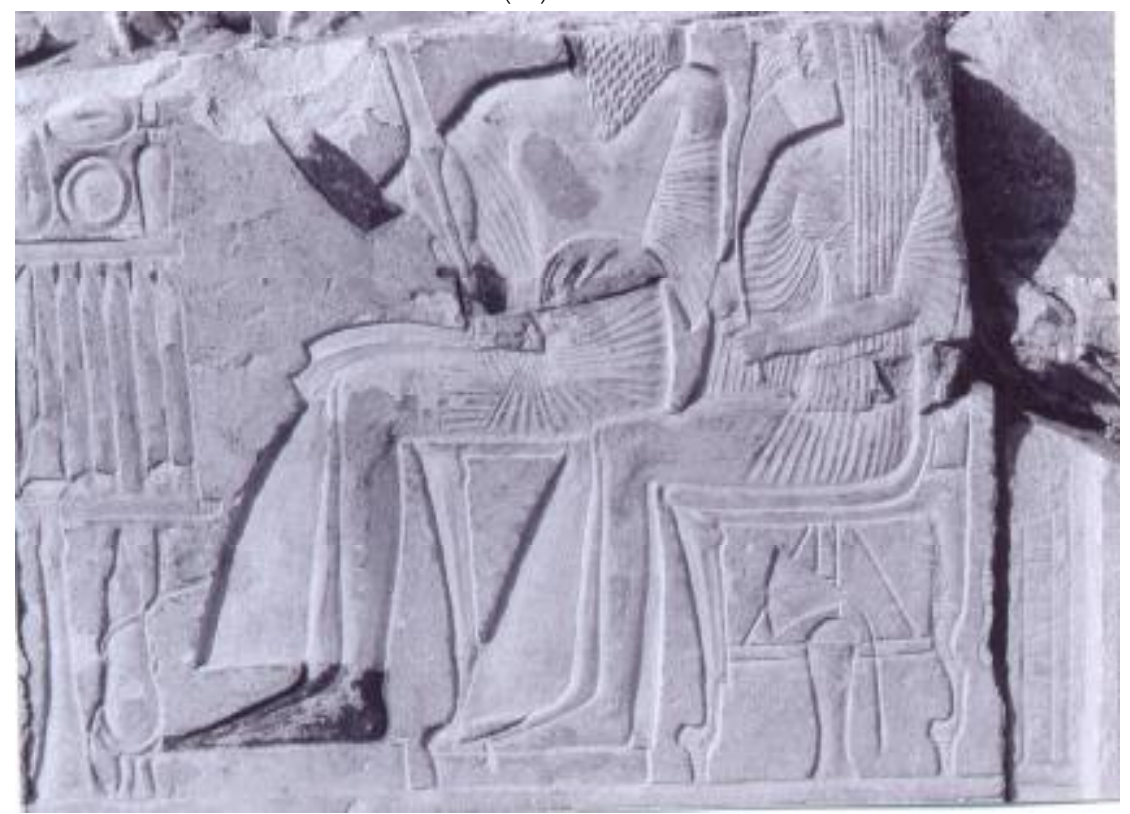

شكل (r) - (r) 
دراسات في آثار الوطن العربي 11

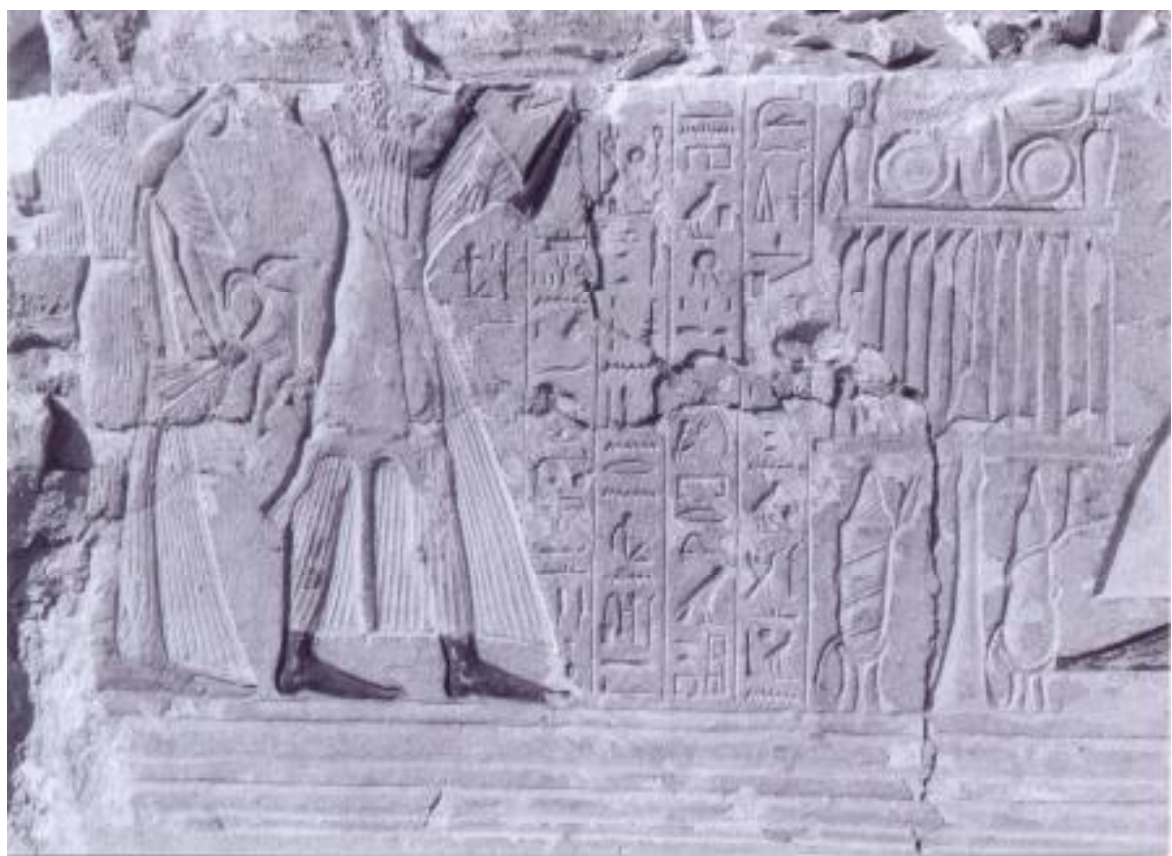

شكل (ع) 
دراسات في آثار الوطن العربي 1

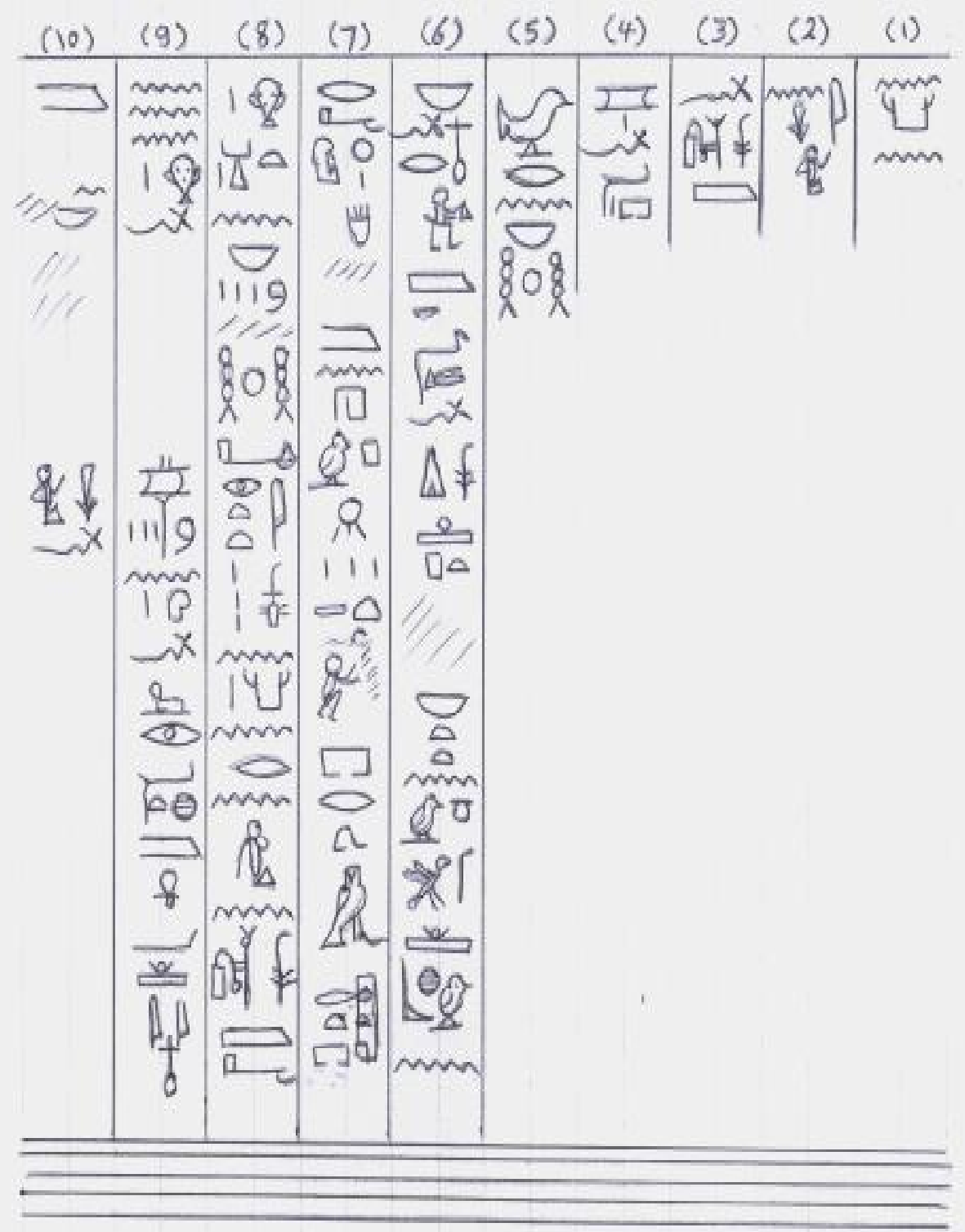

شكل (0) 


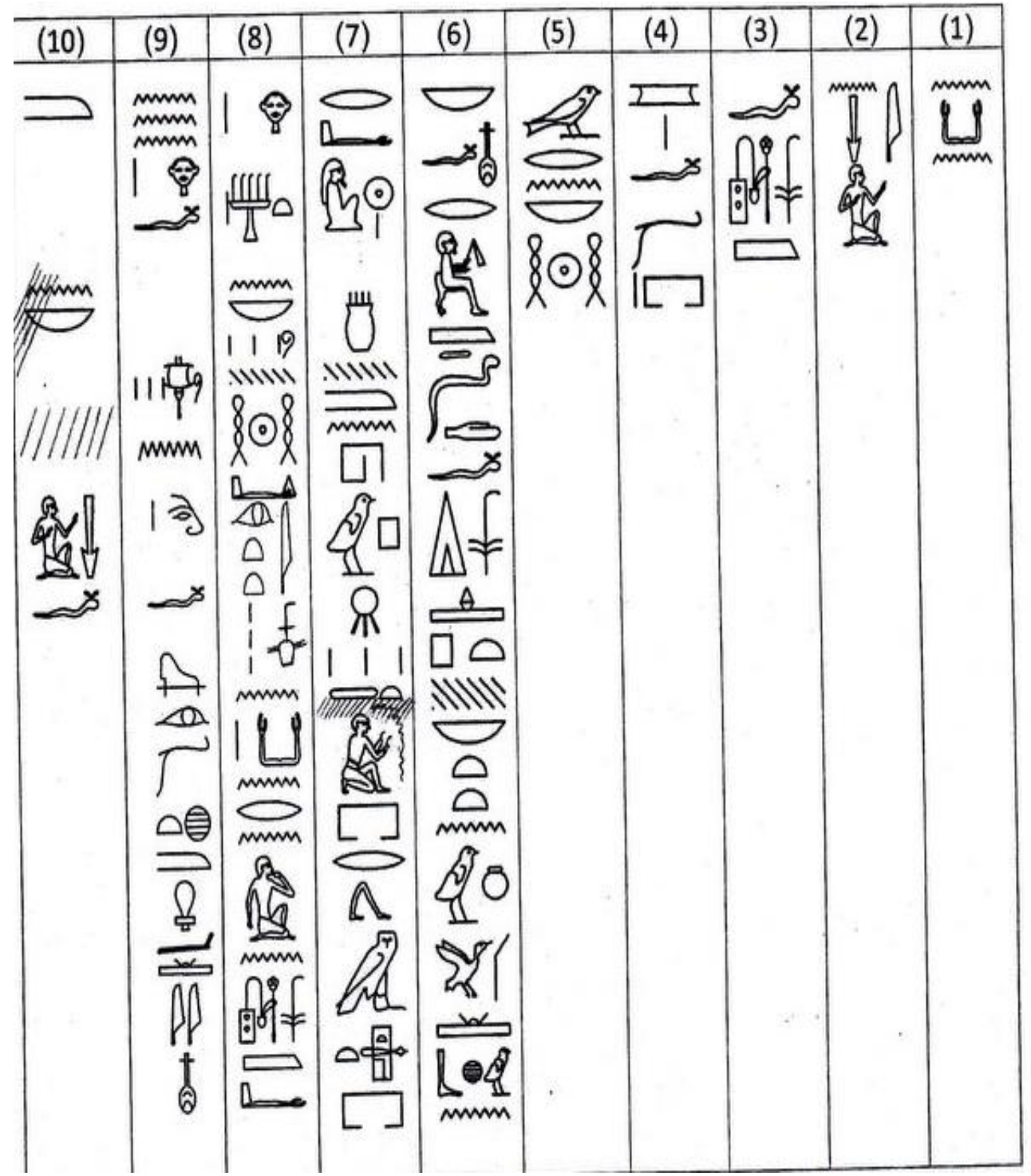

شكل (T) 